\title{
Patterned separator membranes with pillar surface microstructures for improved battery performance
}

R. Gonçalves ${ }^{1 \#}$, D. Miranda ${ }^{2 \#}$, T. Marques-Almeida ${ }^{3,4}$, M. M. Silva ${ }^{1}$, V. F. Cardoso ${ }^{3,5}$,

A. M. Almeida ${ }^{3}$, C. M. Costa ${ }^{1,3, *}$, S. Lanceros-Méndez ${ }^{6,7}$

\#equal contribution

${ }^{1}$ Centro de Química, Universidade do Minho, 4710-057 Braga, Portugal

22Ai- School of Technology, IPCA, 4750-810 Barcelos, Portugal

${ }^{3}$ Centro de Física, Universidade do Minho, 4710-057 Braga, Portugal

${ }^{4}$ Institute of Science and Innovation for Bio-Sustaninability (IB-S), University of Minho, Portugal

${ }^{5}$ CMEMS-UMinho, Universidade do Minho, Campus de Azurém, 4800-058 Guimarães, Portugal

${ }^{6} \mathrm{BCMaterials,} \mathrm{Basque} \mathrm{Center} \mathrm{for} \mathrm{Materials,} \mathrm{Applications} \mathrm{and} \mathrm{Nanostructures,}$ UPV/EHU Science Park, 48940 Leioa, Spain

${ }^{7}$ IKERBASQUE, Basque Foundation for Science, 48009 Bilbao, Spain

Abstract: In order to improve battery performance by tuning battery separator membranes, this work reports on porous poly(vinylidene fluoride-co-trifluoroethylene) $\mathrm{P}(\mathrm{VDF}-\mathrm{TrFE})-$ membranes with surface pillar microstructures. Separators with tailored pillar diameter, height and bulk thickness were fabricated by template patterning and computer simulations, allowing to evaluate the effect of the pillar microstructure characteristics on battery performance. It is shown that the different pillar microstructures of the separators affect the uptake value (150-325\%), ionic conductivity value (0.8-1.6 $\mathrm{mS} \cdot \mathrm{cm}^{-1}$ ) and discharge capacity of the lithium ion batteries (LIB) when compared with the separator without pillars. The experimental charge-discharge behavior demonstrates that the pillar parameters affect battery performance and the best microstructure leading to $80 \mathrm{mAh} \cdot \mathrm{g}^{-1}$ at $2 \mathrm{C}$. Battery performance can be thus optimized by adjusting pillar diameter, height and bulk thickness of the separators keeping its volume constant, as demonstrated also by the simulation results. The parameter with most influence in battery performance is the bulk thickness of the separator, allowing to obtain a maximum discharge capacity value of $117.8 \mathrm{mAh} \cdot \mathrm{g}^{-1}$ at $90 \mathrm{C}$ for a thickness of $0.01 \mathrm{~mm}$. Thus, this work shows that the optimization of the pillar microstructure of the separator membranes allows increasing the capacity towards a new generation of high-performance LIBs. 
Keywords: separator membrane; microstructure; lithium-ion battery; P(VDF-TrFE); theoretical simulation

\section{Introduction}

The growth of world population and the improvement of living standards and mobility result in an increase in the demand for energy that must take into account environmental issues [1]. The mitigation of the environmental impact implies the reduction of greenhouse gas emissions to limit environmental pollution and global warming and, therefore, to promote the use of clean energy sources [2, 3]. Clean energy sources based on renewable sources, such as solar or wind, show an intermittent nature and, once energy is generated, it must be stored in efficient energy storage systems for further use $[4,5]$. Lithium ion batteries (LiBs) are the energy storage devices dominating the market for portable electronic devices and electric / hybrid vehicles and have received increasing attention based on their advantages (lighter, cheaper, higher energy density, less charge lost, no memory effect, higher number of charge/discharge cycles) when compared to other battery systems, such as lead acid, nickel-cadmium battery, or supercapacitors. Thus, this market holds a production of more than 100 million cells / month $[6,7]$ and in strongly linked to mobility.

LiBs are composed by two electrodes (negative and positive) and a porous separator soaked in an electrolyte solution, the constituent materials determining power, safety and environmental impact [8].

Typically, the electrodes are composed by a polymer binder, a conductive additive and an active material that is the main difference between anode and cathode electrodes [9]. The porous separator is an essential component of batteries, as it is placed between the electrodes, preventing electrical short-circuits and controlling lithium ions flow during charging and discharging of the device [10].

The main properties of the porous separator are: low thickness, degree of porosity above $50 \%$ and pore size lower than $1 \mu \mathrm{m}$. Furthermore, it should present excellent chemical, thermal and dimensional stability and good absorption / retention of the electrolyte solution (lithium salts dissolved in organic solvents) [10].

Porous separators are obtained through different polymeric matrices of polyolefins (poly (propylene), PP, and poly (ethylene), PE, fluorinated polymers (poly (vinylidene fluoride), P(VDF), and poly (tetrafluoroethylene), PTFE) and high thermal resistance polymers (polyetherimide, PEI)) [10, 11]. 
It has been demonstrated for porous separators that the ideal value of the degree of porosity is above $50 \%$, the thickness value between $1 \mu \mathrm{m}$ and $32 \mu \mathrm{m}$ [12] and that the pore size is determinant in the growth of lithium dendrites [13].

In addition, in the case of porous separators based on PE and PP, the effect of topological parameters was analyzed, being demonstrated that a high connectivity improves ion gradients [14].

Three dimensional, 3D, batteries allow to increase active mass loading, increase the number of active locations, large surface and short diffusion compared to 2D batteries, leading to an improvement of energy density and power [15]. An example of 3D batteries are interdigitated geometries, which are characterized by high aspect ratio and a large surface area $[16,17]$.

Interdigitated electrodes have been intensively studied [18, 19] and it has been demonstrated how the electrolytic conductivity affects the current distribution [20]. In the case of the electrodes, it was observed that changing electrode height allows to fine tune surface area usage, but has a limited effect on the overall battery performance [18].

The effect of the polymer electrolyte based on lithium bis (trifluoromethanesulfonyl), LiTFSI salt has been also studied by theoretical simulation on 3D batteries, showing that battery geometry and, in particular, distance between the current collectors, is determinant in improving local currents but also in the heat generation, that can be an issue on battery performance and safety [21].

Considering the role of the separator in battery performance, experimental and theoretical studies in differently microstructured 3D separators, including hexagons, lines, zig-zags and pillars surface microstructures, demonstrated that micropatterning allows to improve the discharge capacity efficiency in $804 \%$, when compared to batteries with non-patterned separators [22].

As the pillar geometry is one of the most interesting for improving battery performance, the goal of this work is to evaluate the effect of the pillar diameter, pillar height and the bulk thickness of the separator on the battery performance. Different pillars geometries were produced by surface micropatterning and their morphology, structural and electrochemical properties were determined.

Further, a theoretical simulation was also carried out within an electrochemical model based on the Newman / Doyle / Fuller equations. 


\section{Experimental \\ 2.1.Materials}

Epoxy-based negative photoresist SU-8 100 and SU-8 developer were acquired from Microchem. Polydimethylsiloxane (PDMS) Sylgard® 184 was purchased from Dow Corning and isopropyl alcohol (IPA) from Sigma Aldrich. Poly(vinylidene fluoride) $\mathrm{P}(\mathrm{VDF})$, Solef 5130 and poly(vinylidene fluoride-co-trifluoroethylene) - P(VDF-TrFE 70/30 (30 mol\% trifluoroethylene) were acquired from Solvay and carbon black (Super P-C45) and C-LiFePO 4 from Timcal Graphite \& Carbon and Phostech Lithium, respectively. N,N-dimethylformamide (DMF) and N-methyl-2-pyrrolidone (NMP) with 99.9\% purity were obtained from Merck and Fluka, respectively, and lithium hexafluorophosphate salt in ethylene carbonate and dimethyl carbonate, EC:DMC 1:1 vol., electrolyte ( $\left.\mathrm{LiPF}_{6}-\mathrm{EC}-\mathrm{DMC}, 1 \mathrm{M}\right)$ were purchased from Solvionic. All chemicals and solvents were used as received.

\subsection{Pillars micropatterned polymer membranes fabrication}

\subsubsection{Processing of $S U-8$ and PDMS molds}

SU-8 microstructures with area of $2 \mathrm{~cm}^{2}$ were fabricated by photolithography and consist of arrays of pillars with the different dimensions described in Table 1. These microstructures were used for the fabrication of flexible and chemically resistant PDMS molds by replica molding for the subsequent processing of microstructured PVDF-TrFE membranes. A detailed protocol for the fabrication of SU-8 and PDMS molds with the parameters of each processing step according to dimensions can be found in $[22,23]$.

In order to keep constant the volume of the separators, variation in the spacing between the pillars and their diameter have been evaluated, while preserving the height of the pillars for the different separators.

Table 1- Dimensions of the pillars comprising the different SU-8 molds.

\begin{tabular}{ccccc}
\hline Sample & $\begin{array}{c}\text { Diameter / } \\
\mathbf{m m}\end{array}$ & $\begin{array}{c}\text { Height / } \\
\mathbf{m m}\end{array}$ & $\begin{array}{c}\text { Spacing between } \\
\text { pillars / } \mathbf{m m}\end{array}$ & Volume $/ \mathbf{~ m m}^{\mathbf{3}}$ \\
\hline $\mathrm{A}$ & 0.070 & 0.040 & 0.38 & 0.104 \\
\hline $\mathrm{B}$ & 0.130 & 0.055 & 0.26 & 0.104 \\
\hline $\mathrm{C}$ & 0.145 & 0.050 & 0.02 & 0.104
\end{tabular}


In short, clean standard microscope glass slides $(26 \times 76 \mathrm{~mm})$ were used as substrates for SU-8 deposition through spin-coating (Polos 200, ATP GmbH, Bienenbüttel, Germany). After a pre-back step at a controlled heating rate of $2.5^{\circ} \mathrm{C} \cdot \mathrm{min}^{-1}$ (Präzitherm PZ23-2), the deposited SU-8 films were exposed to UV light using patterned photolithographic masks previously designed and acquired from Microlitho and then post-baked at the same heating rate. At the end of the processing, the patterned SU-8 films were immersed in SU8 developer to remove the unexposed SU-8, washed with IPA and gently dried with compressed air. Then, aluminum adhesive tape was used to create walls around the glass slides in order to confine the PDMS solution. $5 \mathrm{~g}$ of degassed PDMS mixture (1/10 wt.\% curing agent/base) was gently dispensed in each of the microstructured SU-8 molds, left to rest for $10 \mathrm{~min}$, cured for more $30 \mathrm{~min}$ at $100{ }^{\circ} \mathrm{C}$, left to cool to room temperature and finally detached carefully from the SU-8 mold. In addition to the microstructured PDMS molds, flat PDMS films were also fabricated using non-patterned SU-8 molds. The latter were properly cut to create walls around the PDMS microstructures, glued using uncured PDMS solution and cured for $1 \mathrm{~h}$ at $100{ }^{\circ} \mathrm{C}$. The structured-free PDMS molds were fabricated to produce flat $\mathrm{P}(\mathrm{VDF}-\mathrm{TrFE})$ membranes.

\subsubsection{Processing of patterned $P(V D F-T r F E)$ membranes}

$\mathrm{P}(\mathrm{VDF}-\mathrm{TrFE})$ powder was dissolved in DMF at a copolymer volume fraction of $8 \%$ under magnetic stirring until a homogeneous and transparent solution was obtained. The solution was slightly heated at $30^{\circ} \mathrm{C}$ during the first $15 \mathrm{~min}$, to accelerate the dissolution process, followed by $1 \mathrm{~h}$ at room temperature. Before pouring the $\mathrm{P}(\mathrm{VDF}-\mathrm{TrFE})$ solution, the surface of the PDMS molds were treated by oxygen plasma (Electronic Diener Plasma-Surface-Technology, Zepto) at a power of $100 \mathrm{~W}$ for $20 \mathrm{~min}$, under an oxygen pressure of 0.8 mbar, in order to decrease its surface hydrophobicity and assure the correct spread of the polymeric solution through the PDMS microstructures. The copolymer solution was then poured in the treated PDMS molds and left to dry for 7 days at $25^{\circ} \mathrm{C}$ in an air oven (JP Selecta 200208) to guarantee a slow and controlled evaporation of the solvent and thus to obtain a porous morphology [24]. After complete crystallization of the polymer, the flat and microstructured $\mathrm{P}(\mathrm{VDF}-\mathrm{TrFE})$ membranes were carefully peeloff from the molds and stored for posterior characterization and performance evaluation. PDMS molds were gently cleaned with acetone and stored for reuse. The total thickness of the samples is around $500 \mu \mathrm{m}$. 


\subsection{Materials and microstructures characterization}

SU-8 and PDMS molds were evaluated during processing by means of a stereomicroscope Leica M80 and their dimensions confirmed using a surface perfilometer Veeco-Dektak 150. Microstructured P(VDF-TrFE) membranes were evaluated in terms of topography and morphology by scanning electron microscopy (SEM) Quanta 650 FEG from ThermoFisher scientific. Their crystalline phase was confirmed by Fourier transformed infrared spectroscopy in the attenuated total reflection mode (FTIR-ATR), using a Spectrum Two spectrometer (PerkinElmer). Measurements were performed with 64 scans between 400 and $4000 \mathrm{~cm}^{-1}$ at a resolution of $4 \mathrm{~cm}^{-1}$. The porosity of the membranes was assessed by the pycnometer method, as reported in [25].

The contact angle of the microstructured $\mathrm{P}(\mathrm{VDF}-\mathrm{TrFE})$ membranes was evaluated at room temperature using a Data Physics OCA20 apparatus using ultra-pure water and the electrolyte solution as drop test liquid. The liquid drops $(3 \mu \mathrm{L})$ were deposited on the membrane surface and six measurements were performed in different zones of the membranes.

The membranes were immersed in the liquid electrolyte, consisting in a $1 \mathrm{M}$ solution of LiPF $_{6}$ in EC-DMC (1:1) and the uptake was evaluated by equation 1 :

$$
\varepsilon=\left(\frac{M-M_{0}}{M_{0}}\right) \times 100
$$

where $\varepsilon$ is the uptake percentage of the electrolyte solution, $M_{0}$ is the membrane weight and $M$ is the mass of the membrane after immersion in the electrolyte solution.

The ionic conductivity of the microstructured $\mathrm{P}(\mathrm{VdF}-\mathrm{TrFE})$ membranes was determined by impedance spectroscopy measurements carried out at $25^{\circ} \mathrm{C}$ on gold/membrane/gold symmetrical cells by applying a $10 \mathrm{mV}$ alternate voltage in the $65 \mathrm{kHz}-500 \mathrm{mHz}$ frequency range using an Autolab PGSTAT-12 (Eco Chemie). The test cells were manufactured using a constant volume support, and the ionic conductivity value $(\sigma)$ was calculated through equation (2):

$$
\sigma=\frac{d}{R_{b} A}
$$

where $R_{b}$ is the electrolyte bulk resistance obtained by interception of the imaginary impedance (minimum value of $Z$ ' ') with the slanted line in the real impedance ( $\left.Z^{\prime}\right), d$ is the thickness and $A$ is the area of the membrane. 


\subsection{Cathode and battery fabrication and evaluation}

Cathode electrodes with $2 \mathrm{mg} \cdot \mathrm{cm}^{-1}$ of active mass loading, $20 \mu \mathrm{m}$ thickness and a porosity of $60 \%$ were processed through the mixture of the active material $\left(\mathrm{LiFePO}_{4}\right)$, the conductive material (Super P-C45) and the polymer binder (P(VDF), in a weight ratio of 80:10:10 (wt.\%) respectively, with $2.25 \mathrm{~mL}$ of DMPU for $1 \mathrm{~g}$ of solid material. After dried in vacuum overnight at $90{ }^{\circ} \mathrm{C}$, the cathodes were transferred to a homemade argon-filled glove box and the batteries assembled. $\mathrm{Li} / \mathrm{C}-\mathrm{LiFePO}_{4}$ half-cells were assembled with a counter-reference electrode of metallic lithium foil ( $8 \mathrm{~mm}$ diameter), a $10 \mathrm{~mm}$ separator porous structure soaked into the EC-DMC LiPF 6 electrolyte and the $8 \mathrm{~mm} \mathrm{LiFePO}_{4}$ electrode film prepared as cathode. Regarding the microstructured P(VDF-TrFE) separators, they were placed with its patterned surface in contact with the cathode electrode by applying a small force within the Swagelok cell.

Galvanostatic charge-discharge tests were carried out in the voltage range from 2.5 to 4.2 $\mathrm{V}$ at different current densities $\left(\mathrm{C} / 8, \mathrm{C} / 5, \mathrm{C} / 2,1 \mathrm{C}\right.$ and $\left.2 \mathrm{C}, \mathrm{C}=170 \mathrm{mAh} \cdot \mathrm{g}^{-1}\right)$ using a Landt CT2001A instrument at room temperature. The activation cycle was performed at C/8. Electrochemical impedance spectroscopy (EIS) of the half-cells before and after cycling was measured with an Autolab PGSTAT12 instrument in the frequency range from 1 MHz to $10 \mathrm{mHz}$ with an amplitude of $10 \mathrm{mV}$. 


\section{Theoretical simulations}

\subsection{Theoretical model}

The theoretical simulations have been performed using an electrochemical model based on the Newman / Doyle / Fuller equations with a thermal model coupled to the lithium ion half-cell structure through the Pseudo-2D model [26]. The equations that govern the operation of the different components of the half-cell battery (cathode and separator) are described in [27-29]. The half-cell structure is composed by lithium foil, the porous microstructured $\mathrm{P}(\mathrm{VDF}-\mathrm{TrFE})$ separator membranes soaked in the electrolyte solution and positive porous cathode electrode based on $\mathrm{Li}_{x} \mathrm{FePO}_{4}$. The porous separator is thus composed by a solid phase (porous polymer) and a liquid phase (free electrolyte), as shown in Figure 1. Battery discharge conditions at different C-rates (1C to $130 \mathrm{C}$ ) are similar in the simulations and the experiments, considering the battery dimensions used in the simulations.

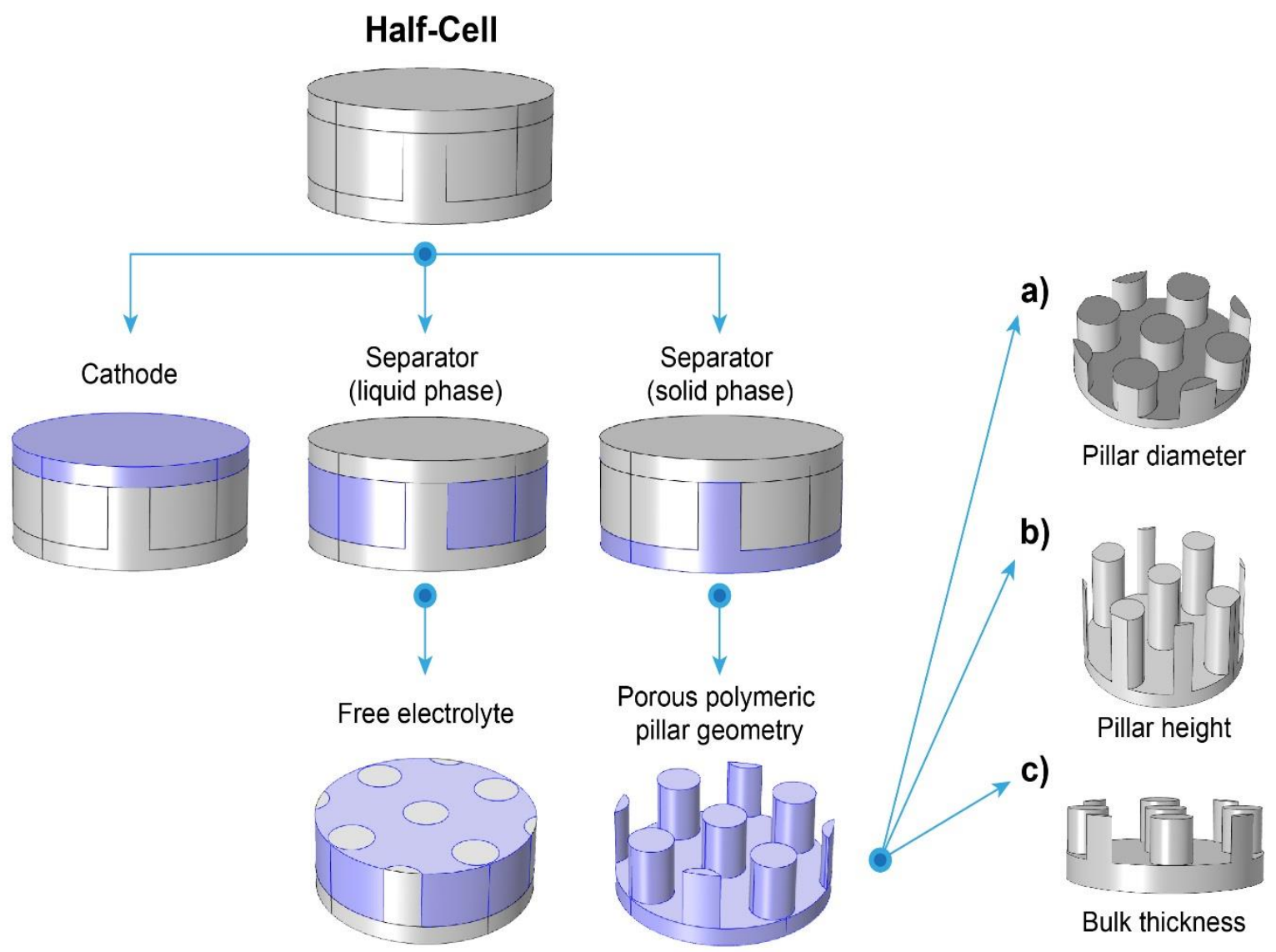

Figure 1 - Schematic representation of the half-cell structure used in the theoretical simulations with variation in the pillar diameter $(0.06$ to $0.16 \mathrm{~mm})(\mathrm{a})$, pillar height $(0.08$ to $0.28 \mathrm{~mm}$ ) (b) and bulk thickness $(0.01$ to $0.08 \mathrm{~mm})(\mathrm{c})$. 
Theoretical simulations were performed keeping constant the volume of solid material (porous polymer material) in order to study the effect of the geometric parameters of the pillar geometry, i.e. pillar diameter $(0.06$ to $0.16 \mathrm{~mm})$ and height $(0.08$ to $0.28 \mathrm{~mm})$ and the bulk thickness $(0.01$ to $0.08 \mathrm{~mm})$, on battery performance. Further, the lithium foil thickness is neglected as the reaction happens just at the surface interface between the anode and the electrolyte. Given the fast formation and recovery speed of the charge imbalance of the double layer capacitance region, which is within a millisecond time scale, the effect of that layer was neglected. Theoretical simulations were carried out through MATLAB scripts of the equations that describe the battery operation. The physical model (shape, dimensions and materials) was built under COMSOL Multiphysics ${ }^{\circledR}$, the mesh size being determined by the order of magnitude of the dimensions of the simulated battery.

\subsection{Specific parameters and initial values}

Table 2 shows the parameter used for the theoretical simulations of the $\mathrm{Li} / \mathrm{C}-\mathrm{LiFePO} 4$ half-cells.

Table 2 - Parameters and initial values used in the simulations. The nomenclature is shown in Annex I.

\begin{tabular}{|c|c|c|c|}
\hline \multicolumn{4}{|c|}{ Parameters and initial values } \\
\hline Parameter & Unit & Separator & Cathode $\left(\mathrm{Li}_{x} \mathrm{FePO}_{4}\right)$ \\
\hline$C_{E, i, 0}$ & $\mathrm{~mol} \cdot \mathrm{m}^{-3}$ & & 3900 \\
\hline$C_{E, i, \max }$ & $\mathrm{mol} \cdot \mathrm{m}^{-3}$ & & 21190 \\
\hline$C_{L}$ & $\mathrm{~mol} \cdot \mathrm{m}^{-3}$ & 1000 & \\
\hline$r$ & $\mathrm{~m}$ & & $8 \times 10^{-6}$ \\
\hline$L_{i}$ & $\mathrm{~m}$ & $150 \times 10^{-6}$ & $20 \times 10^{-6}$ \\
\hline$k_{i}(T)$ & $\mathrm{S} \cdot \mathrm{m}^{-1}$ & a) & a) \\
\hline $\boldsymbol{k}_{e f, i}$ & $\mathrm{~S} \cdot \mathrm{m}^{-1}$ & $k_{i}(T) \times 4.84 \times 10^{-2}$ & $k_{i}(T) \times 0.444^{1,5}$ \\
\hline$k_{t 298,15, i}$ & $\mathrm{~m} \cdot \mathrm{s}^{-1}$ & & $2 \times 10^{-11}$ \\
\hline$k_{t, i}(T)$ & $\mathrm{m} \cdot \mathrm{s}^{-1}$ & & b) \\
\hline$D_{i}(T)$ & $\mathrm{m}^{2} \cdot \mathrm{s}^{-1}$ & c) & c) \\
\hline$D_{e f, i}$ & $\mathrm{~m}^{2} \cdot \mathrm{s}^{-1}$ & $D_{i}(T) \times 4.84 \times 10^{-2}$ & $D_{i}(T) \times 0.444^{1,5}$ \\
\hline$D_{L I}$ & $\mathrm{~m}^{2} \cdot \mathrm{s}^{-1}$ & & $3.2 \times 10^{-13}$ \\
\hline$D_{L I}(T)$ & & & d) \\
\hline Brugg or $p$ & & 8.5 & 1.5 \\
\hline$\varepsilon_{f, i}$ & & & 0.259 \\
\hline$\varepsilon_{i}$ & & 0.70 & 0.444 \\
\hline$\tau$ & & 3.8 & \\
\hline$\sigma_{i}$ & $\mathrm{~S} \cdot \mathrm{m}^{-1}$ & & 11.8 \\
\hline
\end{tabular}




\begin{tabular}{|c|c|c|c|}
\hline$i_{1 C}$ & $\mathrm{~A} \cdot \mathrm{m}^{-2}$ & 17.5 & \\
\hline$F$ & $\mathrm{C} \cdot \mathrm{mol}^{-1}$ & 96487 & \\
\hline $\boldsymbol{R}$ & $\mathrm{J} \cdot \mathrm{mol}^{-1} \cdot \mathrm{K}^{-1}$ & 8.314 & \\
\hline$E_{a d, i}$ & $\mathrm{~J} \cdot \mathrm{mol}^{-1}$ & & $39 \times 10^{3}$ \\
\hline$E_{a k, i}$ & $\mathrm{~J} \cdot \mathrm{mol}^{-1}$ & & $29 \times 10^{3}$ \\
\hline$T$ & $\mathrm{~K}$ & 298.15 & 298.15 \\
\hline & & \multicolumn{2}{|c|}{ Simulations } \\
\hline Parameter & Unit & Validation tests & Theoretical tests \\
\hline$d_{b a t t}$ & $\mathrm{~m}$ & $10 \times 10^{-3}$ & $486 \times 10^{-6}$ \\
\hline
\end{tabular}

Auxiliary equations:

a) Ionic conductivity as a $\left.k_{l}(T)=c \quad\left(\begin{array}{llll}10.5+(0.0740 & T\end{array}\right)\left(\begin{array}{lll}(6.96 & 10^{5}\end{array}\right)\left(T^{2}\right)\right)+\left(\begin{array}{lll}0.668 & c\end{array}\right)$

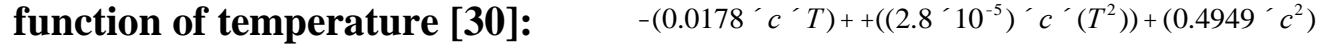

$\left(\begin{array}{llll}(8.86 & \left.10^{4}\right) & \left.\left.\left(c^{2}\right)(T)\right)\right)^{2}\end{array}\right.$

b) Reaction rate coefficient [31]:

$$
k_{L i}(T)=k_{t 298,15 i} e^{E_{a k, c} / R}\left(\frac{1}{T} \frac{1}{298.15}\right)
$$

c) Diffusion coefficient as a function of temperature [30]:
d) Diffusion coefficient of $\mathrm{Li}$ ions [31]:$$
D_{L i}(T)=D_{t 298,15 i} e^{E_{a d, c} / R}\left(\frac{1}{T} \frac{1}{298.15}\right)
$$

$$
D_{l}(T)=10^{\left((0.22 c) 4.43\left(\left(\frac{54}{T 2295 c}\right)\right)\right)}
$$

Table 3 shows the geometrical parameter values of the pillar (diameter, height and base thickness) used in the theoretical simulation for a constant volume of solid material.

Table 3 - Geometrical parameter values corresponding to the different battery separators.

\begin{tabular}{|c|c|c|c|c|c|c|c|}
\hline \multicolumn{8}{|c|}{ Geometrical parameters of the pillar microstructured separators } \\
\hline \multirow{2}{*}{$\begin{array}{c}\text { Geometric } \\
\text { parameter } \\
\text { variation }\end{array}$} & \multirow{2}{*}{ Battery } & \multicolumn{2}{|c|}{ Pillar Diameter } & \multicolumn{2}{|c|}{ Pillar Height } & \multicolumn{2}{|c|}{ Pillar Base Thickness } \\
\hline & & Unit & Value & Unit & Value & Unit & Value \\
\hline \multirow{6}{*}{$\begin{array}{c}\text { Pillar } \\
\text { diameter } \\
\text { variation } \\
(D p)\end{array}$} & 1 & \multirow{6}{*}{$\mathrm{mm}$} & 0.06 & \multirow{6}{*}{$\mathrm{mm}$} & \multirow{6}{*}{0.12} & \multirow{6}{*}{$\mathrm{mm}$} & \multirow{6}{*}{0.04} \\
\hline & 2 & & 0.08 & & & & \\
\hline & 3 & & 0.10 & & & & \\
\hline & 4 & & 0.12 & & & & \\
\hline & 5 & & 0.14 & & & & \\
\hline & 6 & & 0.16 & & & & \\
\hline \multirow{6}{*}{$\begin{array}{c}\text { Pillar } \\
\text { Height } \\
\text { variation } \\
(H p)\end{array}$} & 7 & \multirow{6}{*}{$\mathrm{mm}$} & \multirow{6}{*}{0.10} & \multirow{6}{*}{$\mathrm{mm}$} & 0.08 & \multirow{6}{*}{$\mathrm{mm}$} & \multirow{6}{*}{0.04} \\
\hline & 8 & & & & 0.12 & & \\
\hline & 9 & & & & 0.16 & & \\
\hline & 10 & & & & 0.2 & & \\
\hline & 11 & & & & 0.2485 & & \\
\hline & 12 & & & & 0.28 & & \\
\hline \multirow{5}{*}{$\begin{array}{c}\text { Base } \\
\text { Thickness } \\
\text { variation } \\
(T b)\end{array}$} & 13 & \multirow{5}{*}{$\mathrm{mm}$} & \multirow{5}{*}{0.10} & \multirow{5}{*}{$\mathrm{mm}$} & \multirow{5}{*}{0.12} & \multirow{5}{*}{$\mathrm{mm}$} & 0.01 \\
\hline & 14 & & & & & & 0.02 \\
\hline & 15 & & & & & & 0.04 \\
\hline & 16 & & & & & & 0.06 \\
\hline & 17 & & & & & & 0.08 \\
\hline
\end{tabular}
The identification of each symbol is provided in the nomenclature section (Annex I). 


\section{Results and discussion}

\subsection{Morphology, physical-chemical and electrical properties}

The surface and cross-section SEM images of the microstructured P(VDF-TrFE) membranes are presented in Figure 2.
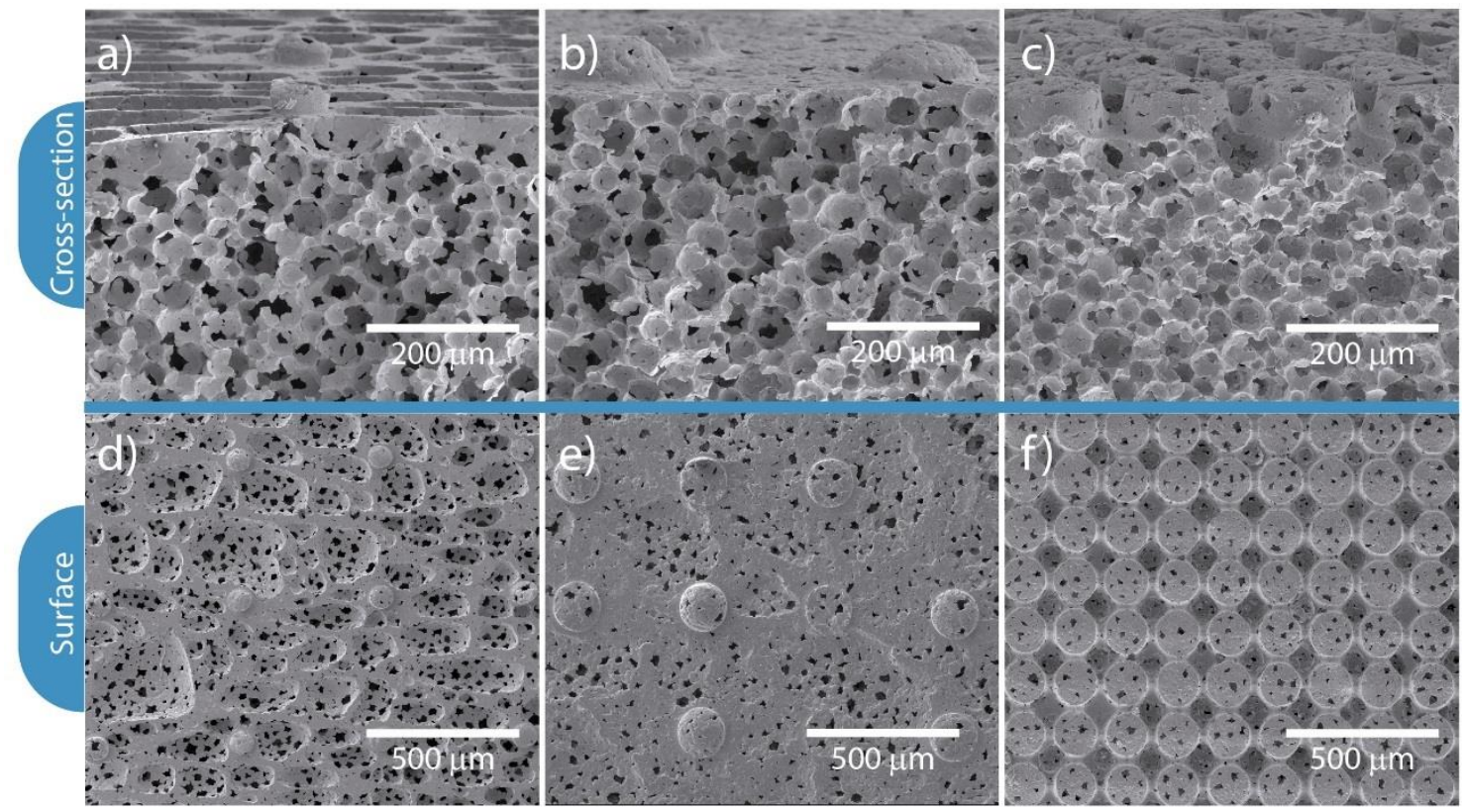

Figure 2 - Surface (below) and cross-section (above) morphology images of Sample A (a and d), Sample B (b and e) and Sample C (c and f).

Figure 2 shows that all microstructured $\mathrm{P}(\mathrm{VDF}-\mathrm{TrFE})$ membranes are characterized by a porous morphology composed by arrays of three-dimensional pillars.

The cross-sectional images (Figure 2a)-c)) show that the porous morphology is homogeneous along the thickness of the membranes with interconnected pores of sizes < $5 \mu \mathrm{m}$. In addition, surface images (Figures 2d)-f)) confirm the good pillars distribution along the surface.

Thus, it is confirmed that all $\mathrm{P}(\mathrm{VDF}-\mathrm{TrFE})$ membranes show a patterned pillar microstructure with high porosity $(\sim 80 \%)$ [25] and pore size $<5 \mu \mathrm{m}$, being suitable for separator membranes in lithium ion batteries.

The polymer crystalline phase of the different membranes is identified in the infrared spectra shown in Figure 3a). It is observed that all membranes present the characteristic vibration modes at $841 \mathrm{~cm}^{-1}, 886 \mathrm{~cm}^{-1}$ and $1402 \mathrm{~cm}^{-1}$, confirming that the membranes 
crystalize in the trans TTT' highly polar polymer chain conformation [25], independently of the surface pattern.
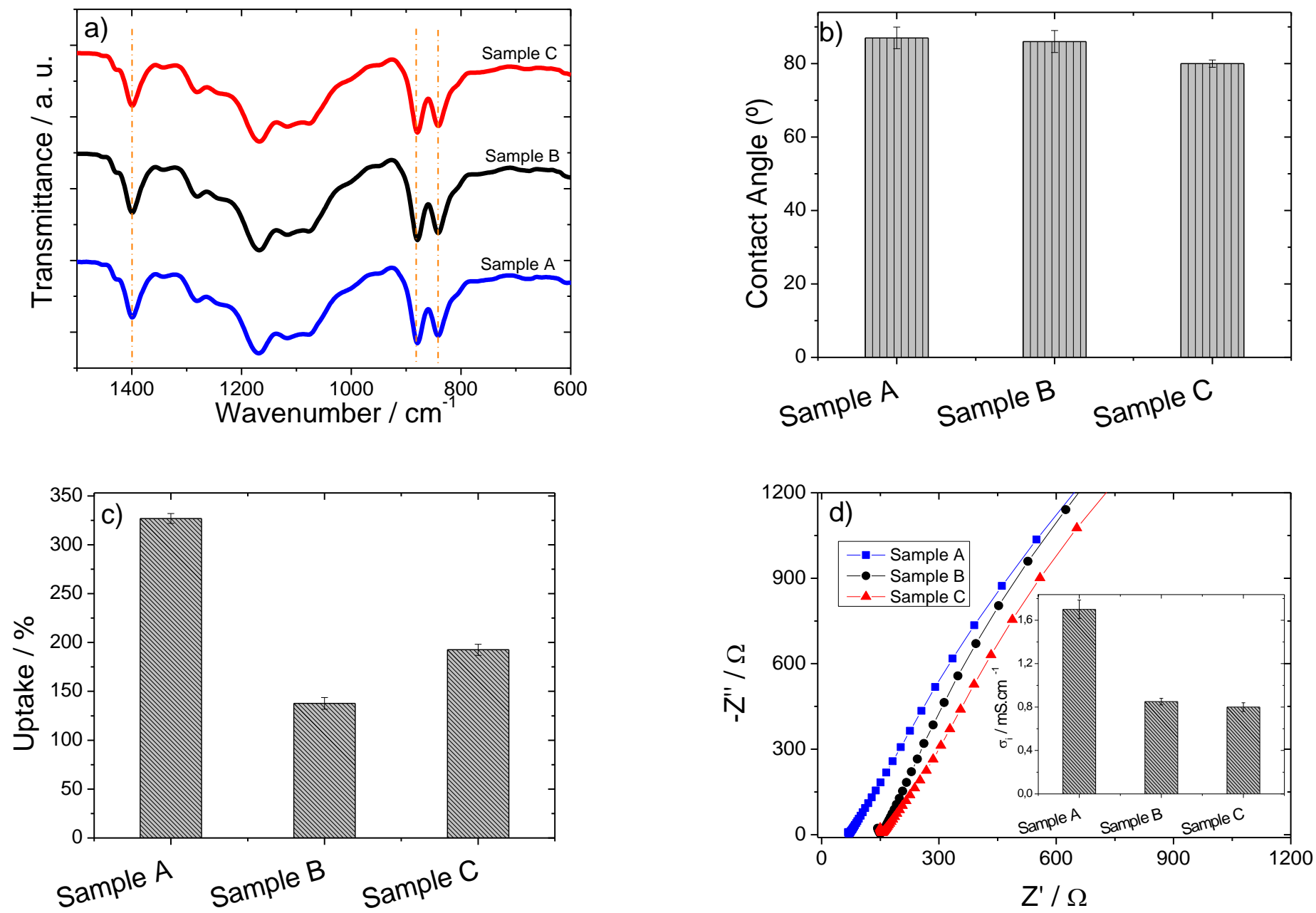

Figure 3 - a) Infrared spectra, b) contact angle, c) uptake behavior and d) impedance response after electrolyte uptake, of the microstructured P(VDF-TrFE) membranes.

It is to notice that the observed crystallization in the highly polar $\beta$ phase for all membranes promotes a faster lithium ion migration within the separator during the charge/discharge of the battery, being therefore a suitable characteristic for battery applications [32].

The wettability of the microstructured $\mathrm{P}(\mathrm{VDF}-\mathrm{TrFE})$ membranes was evaluated by measuring the contact angle with ultra-pure water and electrolyte solution.

Figure $3 b$ ) shows the contact angle for all membranes using ultra-pure water. A hydrophilic behavior is observed for all membranes, identified by a contact angle of $\sim 82$ . 
Regarding the electrolyte solution, after placing the drop on top of the membrane, it is immediately absorbed by the membrane through the interaction between the P(VDFTrFE) chain and the solvent molecules of the electrolyte solution [33]. Therefore, the microstructured P(VDF-TrFE) membranes show good electrolyte affinity, providing ion transport pathways for application in LIBs.

The uptake value of the microstructured $\mathrm{P}(\mathrm{VDF}-\mathrm{TrFE})$ membranes is reported in Figure $3 \mathrm{c})$, where regardless of the structure, all membranes achieve saturation approximately after 1 minute of immersion, which is also related to the high degree of porosity.

In addition, the maximum uptake value (close to 325\%) is obtained for sample A, the pillar structure and, in particular, the spacing between pillars, being a relevant parameter for improving the uptake value. The high uptake value also demonstrates that sample A shows a suitable pore size and well-interconnected pores.

The ionic conductivity of the microstructured P(VDF-TrFE) membranes after the uptake process was determined by impedance spectroscopy, at $25^{\circ} \mathrm{C}$. The corresponding Nyquist plots are presented in Figure 3d). Independently of the pillar's microstructure, the impedance responses exhibits an inclined straight-line (typical of the blocking electrode capacitive behavior) whose intercept with the real axes, Z', provides the P(VDF-TrFE)based electrolyte membrane ionic resistance [34]. The ionic conductivity value was calculated from equation 2 and the value for the different membranes is presented as insert in Figure 3d).

There is a correlation between the uptake value and the ionic conductivity, also correlated to the pillar microstructure. The highest ionic conductivity value $(1.6 \mathrm{mS} / \mathrm{cm})$ is observed for sample A, as this morphology shows good electrolyte retention, resulting in fast transport properties.

Parameters such as high ionic conductivity and uptake values are important to obtain high performance separator membranes, being in the present case $\sim 0.8-1.6 \mathrm{mS} \cdot \mathrm{cm}^{-1}$ and 150 $325 \%$, respectively, depending on the separator geometry [22]. In fact, in addition to these parameters, it has been demonstrated that the contact area between the electrolyte and the separator is an important parameter determining the performance of a battery separator, as increasing contact area improves ion diffusion [22]. This parameter is studied in detail in this work through the variation of the geometric parameters of the pillars while maintaining constant the volume of the membranes. 


\subsection{Battery performance}

To evaluate the effect of the geometric parameter's variations of the pillar microstructured $\mathrm{P}(\mathrm{VDF}-\mathrm{TrFE})$ membranes in battery performance, cathodic half-cells were fabricated and the charge-discharge characteristics curves evaluated, as presented in Figure 4a).

Figure 4a) shows the fifth charge-discharge curve profiles at different $\mathrm{C}$ rates $(\mathrm{C} / 8, \mathrm{C} / 5$, $\mathrm{C} / 2,1 \mathrm{C}$ and 2C) for Sample A at room temperature and in the voltage range between 2.5 to $4.2 \mathrm{~V}$. For the other microstructured P(VDF-TrFE) membranes, the charge/discharge curve profiles are similar to the ones presented in Figure 4a).
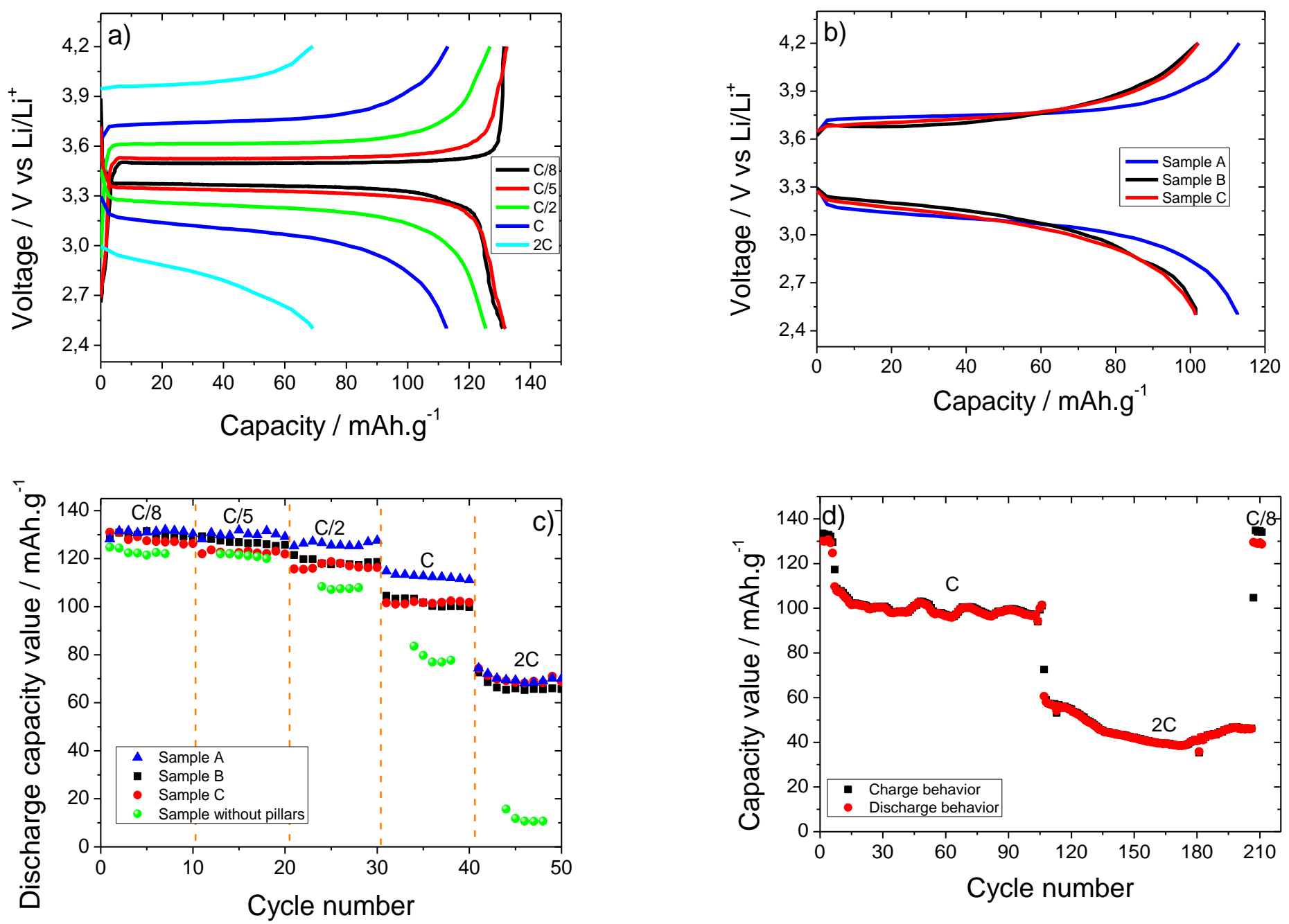

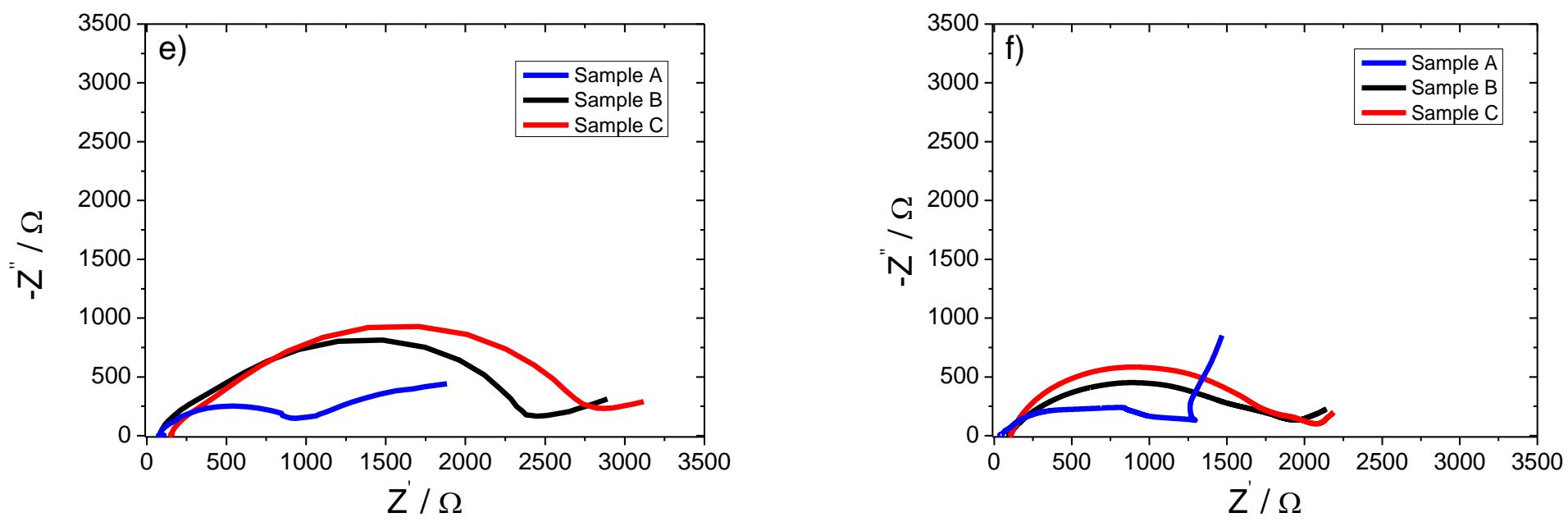

Figure 4 - a) Fifth charge-discharge profiles at different C-rates for Sample A. b) Fifth charge/discharge curve at 1C-rate for the different membranes. c) Rate performance as a function of the number of cycles for the different membranes and comparison with the sample without pillars. d) Cycle life behavior for Sample A at 1C and 2C-rate. EIS spectra e) before and $\mathrm{f}$ ) after cycling for all microstructured $\mathrm{P}(\mathrm{VDF}-\mathrm{TrFE})$ membranes.

These charge/discharge profile curves represent the removal and insertion of lithium, respectively, which occurs in the $\mathrm{C}-\mathrm{LiFePO}_{4}$ active material through redox $\mathrm{Fe}^{2+} / \mathrm{Fe}^{3+}$ reactions [35], independently of the C-rate. The discharge capacity values for Sample A are 131.0, 131.6, 125.0, 113.0 and $69.0 \mathrm{mAh} \cdot \mathrm{g}^{-1}$ at $\mathrm{C} / 8, \mathrm{C} / 5, \mathrm{C} / 2,1 \mathrm{C}$ and $2 \mathrm{C}$-rates, respectively. This membrane has excellent electrochemical values at high $\mathrm{C}$-rate $(2 \mathrm{C}$, charge and discharge in half an hour).

Figure $4 b$ ) shows the fifth charge/discharge curve at 1C-rate for the different microstructured $\mathrm{P}(\mathrm{VDF}-\mathrm{TrFE})$ membranes, the voltage profile being very similar for all the samples. At $1 \mathrm{C}$ rate, Sample A shows a higher discharge capacity value $\left(113 \mathrm{mAh} \cdot \mathrm{g}^{-}\right.$ $\left.{ }^{1}\right)$ than the other samples $\left(102 \mathrm{mAh} \cdot \mathrm{g}^{-1}\right)$, which is related to the higher ionic conductivity value and different contact area between the electrolyte and the separator, leading to different battery performance. Figure $4 b$ ) also shows similar battery performance for samples B and C, demonstrating the low influence of the diameter parameter. Figure 4c) shows the discharge rate performance of all microstructured $\mathrm{P}(\mathrm{VDF}-\mathrm{TrFE})$ membranes compared to the membrane without pillars at the different rates from $\mathrm{C} / 8$ to $2 \mathrm{C}$-rates in which 10 cycles were evaluated for each rate. Independently of the C-rate, all membranes are very stable over cycling. Differences on discharge capacity value are observed after $\mathrm{C} / 5$ rate for all membranes, the membrane with the highest discharge capacity value for 
all C-rates being Sample A. From Figure 4c), it is observed that the patterned pillar structure leads to an increase in battery performance, since the pillars allow a more efficient diffusion of the ions due to the larger surface area interaction with the electrolyte. To demonstrate the cycling stability of this sample at high C-rates (1C and 2C), Figure 4d) shows the charge and discharge values for both rates in more than 100 cycles. After 100 cycles, the discharge capacity at $1 \mathrm{C}$ and 2C-rates are 102 and $46 \mathrm{mAh} \cdot \mathrm{g}^{-1}$, respectively, with small capacity fade $(<10 \%)$ and coulombic efficiency around $100 \%$. Thus, a good capacity stability and excellent capacity retention are obtained.

EIS measurements of the microstructured P(VDF-TrFE) membranes before (Figure 4e) and after cycling (Figure 4f) in cathode half-cells were performed to evaluate the interfacial properties between the separator/electrolyte and the cathode electrode.

Regardless of the cycling of the membranes, the Nyquist plots presented in Figure 4e-f) are characterized by a semicircle in the high-medium frequency range, which describes the total resistance composed of ohmic, contact film and charge transfer reaction, and a linear line in the low frequency range which is related to the lithium ion diffusion within the active material present in the cathode electrode [36].

For before cycling (Figure 4e), the overall resistance for each separator was 946, 2243 and $2874 \Omega$ for Sample A, B and C, respectively.

With respect to the effect of cycling on the overall resistance of the different membranes, it is observed that the resistance increases for all samples due to the formation of a solid electrolyte interface (SEI). This stable SEI layer facilitates lithium ions transport with increasing number of cycles and reduces lithium ion diffusion.

Thus, the different microstructured P(VDF-TrFE) membranes show different SEI formations and, consequently, cycling performance, which is due to the different contact area between separator and electrolyte. In the following, theoretical simulations will allow to properly understand the observed variations. 


\subsection{Simulation results}

To evaluate the applicability of the theoretical simulation for the calculation of the battery performance for the batteries with different microstructured $\mathrm{P}(\mathrm{VDF}-\mathrm{TrFE})$ membranes, a comparison of the simulated and experimental data from Sample A at C/5 rate was performed (Figure 5). The results are similar for the rest of the samples.

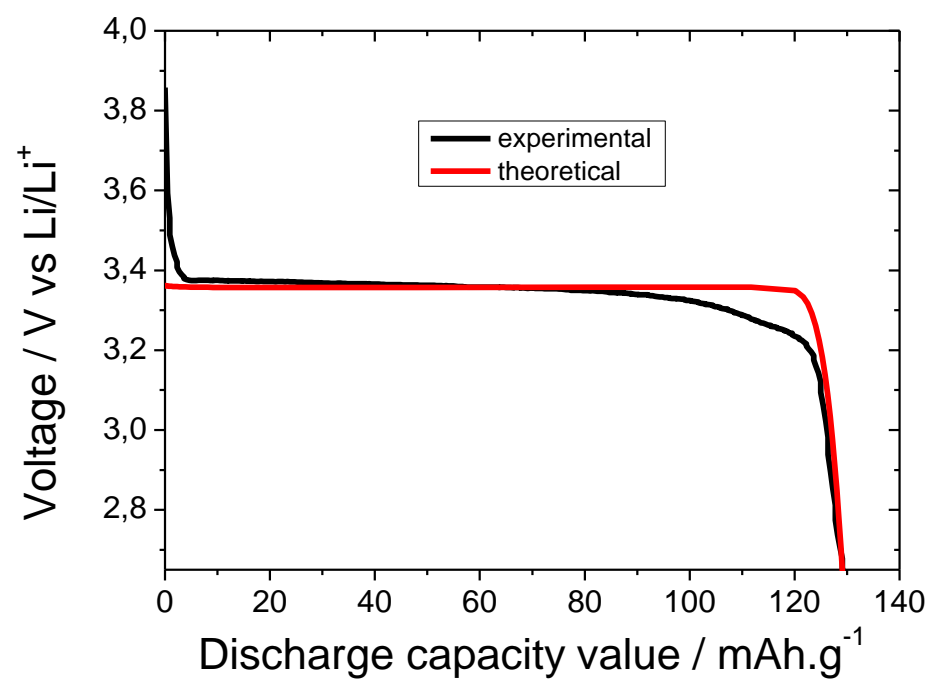

Figure 5 - Experimental and theoretical discharge profile curves for the battery prepared with the Sample A microstructured separator membrane.

Figure 5 shows a good agreement between the experimental and theoretical data with slight variations in the plateau curve, which may be attributed to the electrode parameter (electronic/ionic conductivity value) in the model [37].

Thus, the theoretical simulation model can be used to describe and better understand the effect of the geometrical parameter's variations (diameter, height, and bulk thickness) of the microstructured $\mathrm{P}(\mathrm{VDF}-\mathrm{TrFE})$ membranes in order to obtain high battery performance. In the simulations, the volume of the separator remained constant and the discharge rate values applied were between 1C and 130C-rate for all geometries. 


\subsubsection{Effect of pillar diameter}

The pillar diameter was theoretically evaluated for six batteries with pillar diameter between 0.06 to $0.16 \mathrm{~mm}$, while keeping constant pillar height and bulk thickness of the separator at $0.12 \mathrm{~mm}$ and $0.04 \mathrm{~mm}$, respectively.

Figure 6a) shows the discharge capacity values for the different geometries between 1C to $130 \mathrm{C}-$ rate.

Up to $80 \mathrm{C}$-rate and regardless of the pillar diameter, the discharge capacity value is practically constant, with a slight decrease from $129 \mathrm{mAh} \cdot \mathrm{g}^{-1}$ to $117 \mathrm{mAh} \cdot \mathrm{g}^{-1}$. For rates above $80 \mathrm{C}$, there is a decrease in the discharge capacity values for geometries with higher pillar diameters, which is attributed to an increase of the ionic resistance. In any case, all geometries operate up to $130 \mathrm{C}$-rate.
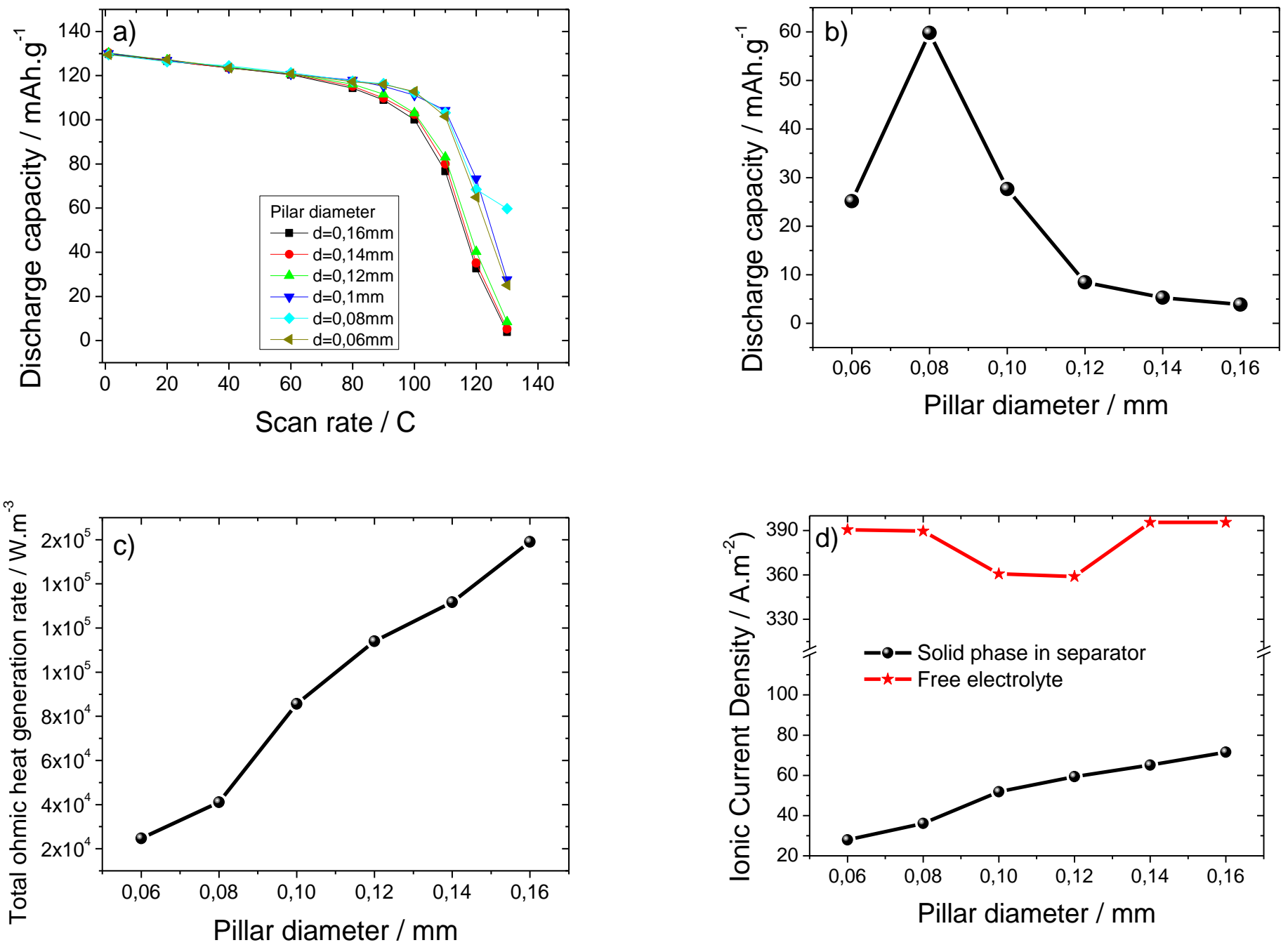

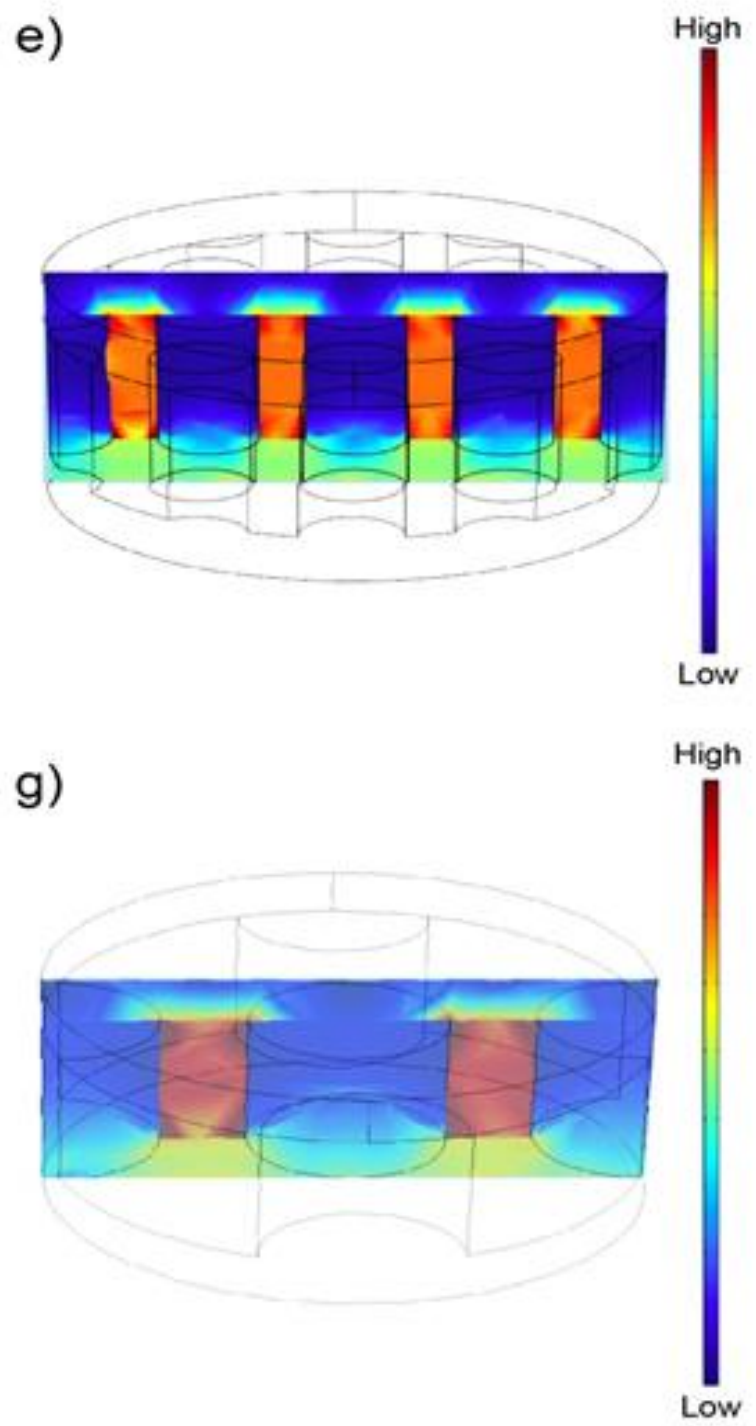

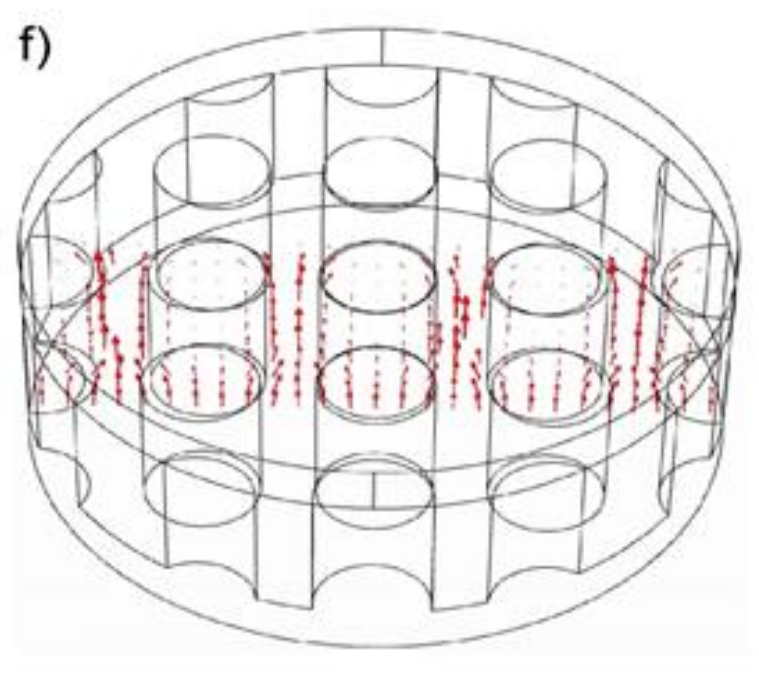

h)

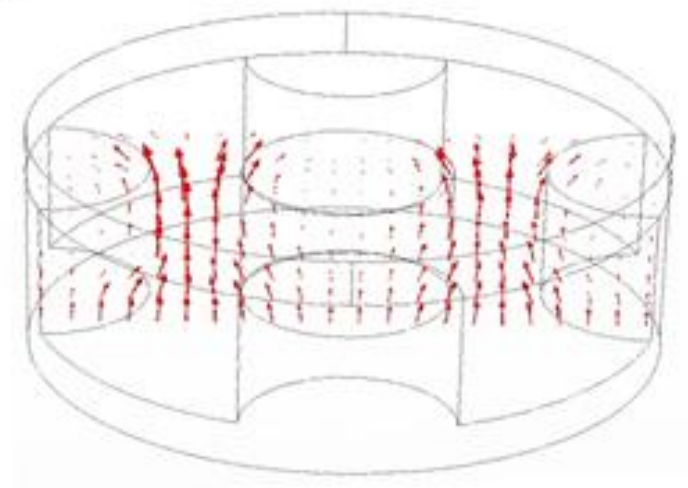

Figure 6 - a) Discharge capacity value as a function of C-rate for the membranes with the different pillar diameters. b) Discharge capacity value, c) Total ohmic heat generation and d) Ionic current density as a function of pillar diameter at 130C-rate. Color mapping of the ionic current density (e and g) and electrolyte current density vectors ( $f$ and $h$ ) for pillar diameters of $0.08 \mathrm{~mm}$ and $0.16 \mathrm{~mm}$, respectively.

Figure 6b) shows the discharge capacity value for different pillar diameters at 130C-rate. It is observed that the discharge capacity value decreases with the increase of the pillar diameter except for the pillar with $0.08 \mathrm{~mm}$ of diameter. This fact is due to the reduction of the interface between solid separator and free electrolyte. Also, the higher discharge capacity value of the sample with $0.08 \mathrm{~mm}$ of pillar diameter is due to the decrease in the volume of the free electrolyte and consequently, to the decrease in the pillars number to keep the separator volume constant. 
Thus, the higher discharge capacity value is associated with the reduction of the contact area between pillars with the bulk separator and the high spacing between the pillars resulting in a larger region for the free electrolyte.

Taking into account that ion mobility produces ohmic heat, Figure 6c) shows the total ohmic heat generated as a function of the pillar diameter evaluated in the solid phase of the separator. It is observed that the total ohmic heat increases with increasing the pillar diameter, the total ohmic heat for the pillar with a diameter of $0.16 \mathrm{~mm}$ being six times larger than for the one with $0.06 \mathrm{~mm}$. The main reason for this fact is due to the increase in the contact area between pillar base and the bulk separator and, consequently, a decrease of the contact area between the free electrolyte and the bulk separator.

Figure 6d) shows the ionic current density for free electrolyte and solid phase of the separator as a function of the pillar diameters, determined at a time that corresponds to $50 \%$ of the total battery discharge time. For the free electrolyte, the ionic current density is practically the same for all pillar diameters (Figure 6d). On the other hand, with respect to the solid phase of the separator, it is observed that the ionic current density increases with the increase of the pillar's diameters due to the increase of the contact area of the pillars with the bulk separator, which implies an increase of the lithium ion number along the discharge process.

Figures 6e) and g) represent the electrolyte current density for the geometries with pillar diameters of $0.08 \mathrm{~mm}$ and $0.16 \mathrm{~mm}$, respectively. Regardless of the pillar diameter it is observed that the density of the ionic current is high in the free electrolyte in relation to the solid phase of the separator.

This higher value of the current density in the free electrolyte implies the existence of an increased ion flow.

Figures 6f) and h) show the electrolyte current density vectors in which the vector magnitude is high in the free electrolyte region. It is also confirmed by the orientation and trajectory of the current density that the lithium ions mainly move through the free electrolyte. 


\subsubsection{Effect of pillar height}

Regarding the pillar height effect, six batteries were tested with different pillars heights from $0.08 \mathrm{~mm}$ to $0.28 \mathrm{~mm}$, keeping the volume constant. In this case, pillar diameter and bulk thickness of the separators were kept constant at $0.10 \mathrm{~mm}$ and $0.04 \mathrm{~mm}$, respectively. Figure 7a) shows the discharge capacity values for the separator membranes with geometries with varying pillar heights at C-rates between $1 \mathrm{C}$ to $130 \mathrm{C}$.

Regardless of the pillar height, it is observed that the value of the discharge capacity is almost the same up to 90C-rate, the value of the discharge capacity decreasing just from $129 \mathrm{mAh} \cdot \mathrm{g}^{-1}$ to $115 \mathrm{mAh} \cdot \mathrm{g}^{-1}$ for the $0.12 \mathrm{~mm}$ to the $0.28 \mathrm{~mm}$ pillar heights, respectively (Figure 7a). Some of the developed geometries with different pillar heights do not operate at 120C- and 130C-rate, so that the comparison of the discharge capacity as a function of pillar height (Figure 7b) is performed at 110C-rate.
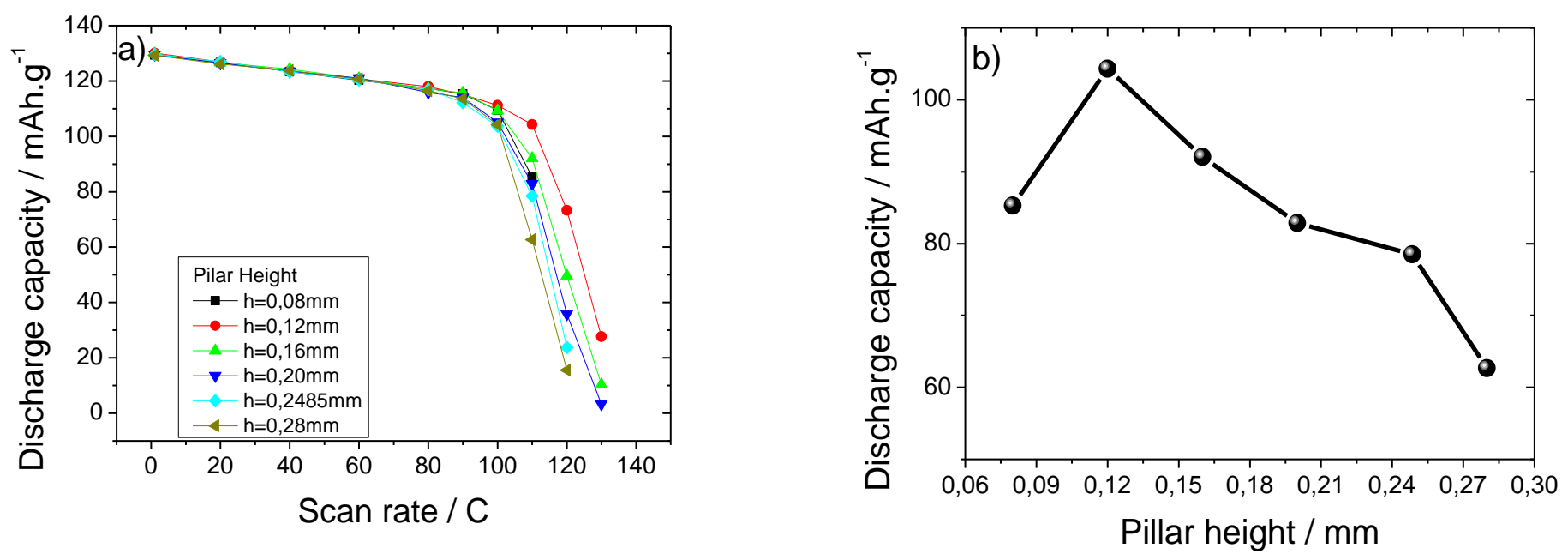

Figure 7 - a) Discharge capacity as a function of C-rate for the separators with different pillar heights and b) as a function of pillar height at 110C.

Figure 7b) shows that the discharge capacity value decreases with increasing the pillar height. According to Figure 1, this fact can be explained by the increased spacing between pillars to keep the volume constant, leading to an increase of the free electrolyte volume, together with an increase of the contact area of the free electrolyte with the solid bottom base of the separator.

Further, there is an important effect on the distance between the current collectors (Figure 8a) as the height of the pillars increases, there is an increase of the distance between the current collectors, leading to an increase in the distance that the ions need to travel for intercalation during the battery discharge process. 
Relatively to the pillar heights between $0.08 \mathrm{~mm}$ and $0.12 \mathrm{~mm}$ (Figure $8 \mathrm{~b}$ ), it is observed that the discharge capacity value increases with increasing pillar heights. In this case, though the distance between the current collectors increases with increasing pillar height, other factors, such as increased pillars spacing, contact area between free electrode and separator and occupied region of the free electrolyte also contribute to the observed battery performance.

In contrast, in the pillar height range from $0.12 \mathrm{~mm}$ to $0.28 \mathrm{~mm}$, the losses associated with increasing distance between the current collectors for increasing pillar height are more significant than the gains associated with increasing spacing between pillars and the area electrolyte / bottom solid base of the separator.

It can be concluded that the battery with the pillar height of $0.12 \mathrm{~mm}$ is the case in which the balance of the different effects leads to a high battery performance when compared to the other batteries with separator membranes with different pillar heights.

Figure $8 \mathrm{~b}$ ) quantifies how the space between the pillars increases with increasing pillar height, while maintaining constant separator volume.
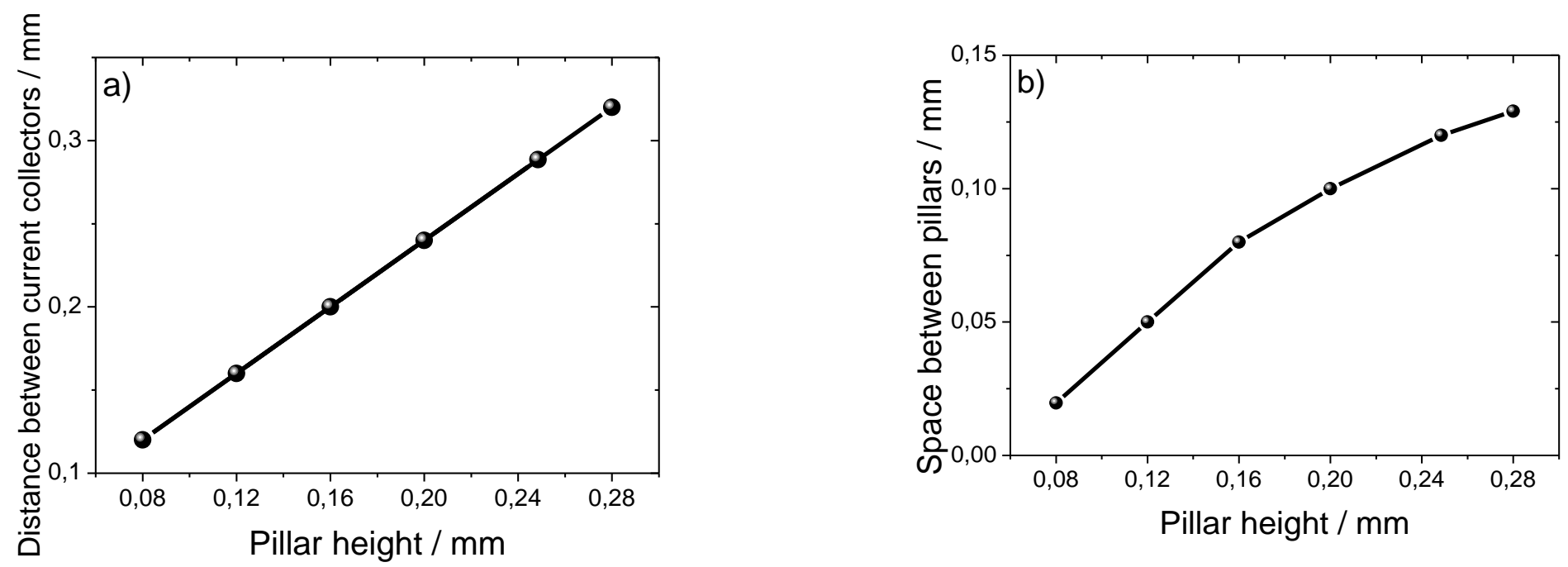

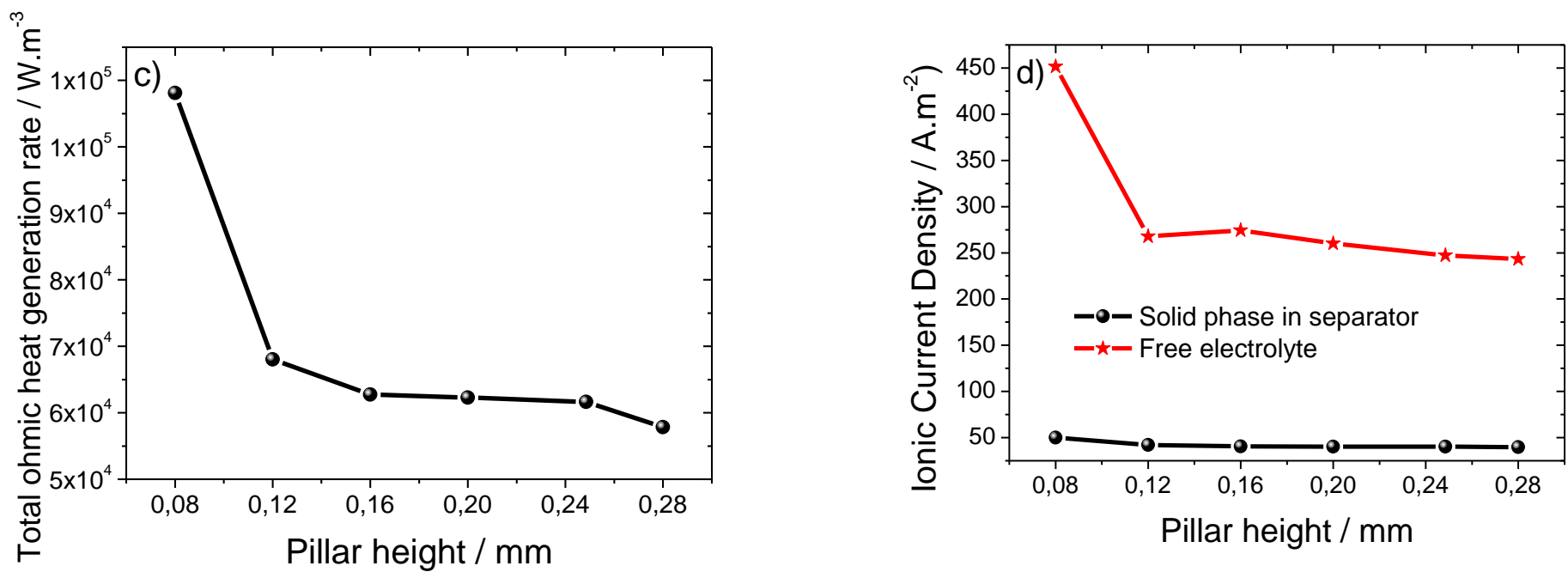

e)
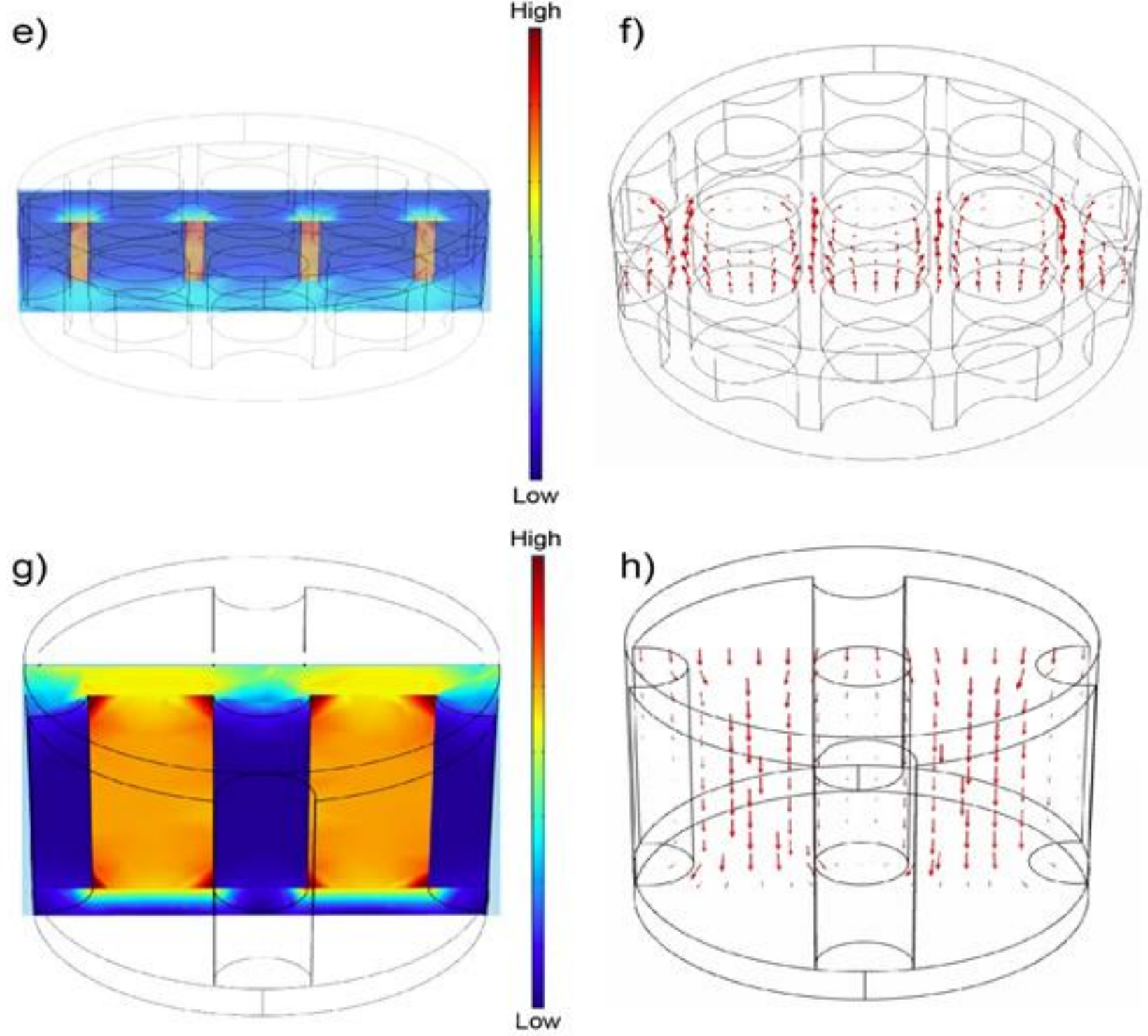

Figure 8 - a) Distance between current collectors, b) space between pillars, c) total ohmic heat generation and d) ionic current density as a function of pillar height at 110C-rate. 
Color mapping of ionic current density (e) and g)) and electrolyte current density vectors (f) and h)) for separator membranes with pillar height of $0.08 \mathrm{~mm}$ and $0.28 \mathrm{~mm}$, respectively.

Figure 8c) shows the total ohmic heat generated decreases with increasing pillar height, which is attributed to the low contact area between the free electrolyte and the solid bottom base of the separator. Further, increasing the number of pillars on the separator surface leads to larger ion uptake by the solid regions of the separator.

Figure 8d) shows the ionic current density for both free electrolyte and solid phase of the separator as a function of the pillar height, determined at a time corresponding to $50 \%$ of the total battery discharge. It is observed that the ionic current density decreases with increasing pillar height and that the ionic current density is higher in the free electrolyte region. This fact is due to the increase in the contact area of the free electrolyte region and the solid base of the separator, which allows easy access of the ions to the free electrolyte, increasing the flow of ions. The increase in the pillar height implies an increase in the volume of the free electrolyte, leading to values close to the ionic current density in the electrolyte in the various pillar heights geometries.

Figure 8e) and g) show the electrolyte current density for the geometries with pillar height of $0.08 \mathrm{~mm}$ and $0.28 \mathrm{~mm}$, respectively, at 110C. It is observed that, regardless of the pillar height, the density of the ionic current is high in the free electrolyte in relation to the solid phase of the separator, due to the higher ion number and ionic mobility.

Figures $8 \mathrm{f}$ ) and $\mathrm{h}$ ) show the magnitude and direction of the ionic current density vectors in the regions of solid phase (pillar) and free electrolyte region, showing that the ionic current density vector magnitude is larger in the free electrolyte region in relation to the solid phase region of the separator (pillars). It is also observed the preferential orientation of the ionic current density vectors in the free electrolyte region. 


\subsubsection{Effect of bulk thickness}

Regarding the effect of bulk thickness variation, five batteries were tested with different bulk thicknesses between $0.01 \mathrm{~mm}$ to $0.08 \mathrm{~mm}$, keeping the volume constant. In these simulations, the pillar diameter and height remain constant at $0.10 \mathrm{~mm}$ and $0.12 \mathrm{~mm}$, respectively, in order to maintain constant the volume of the separator.

Figure 9a) shows the discharge capacity values for the separator geometries with different bulk thickness at C-rates between 1C-rate to 130C-rate.

It is observed that the discharge capacity value for geometries with different bulk thickness of the separator is practically the same up to 60C, i.e, it decreases up to 129 $\mathrm{mAh} \cdot \mathrm{g}^{-1}$ to $120 \mathrm{mAh} \cdot \mathrm{g}^{-1}$ at $1 \mathrm{C}$. As all geometries operate up to $90 \mathrm{C}$-rate, Figure $9 \mathrm{~b}$ ) shows the discharge capacity value as a function of the bulk thickness of the separators at this 90C-rate.
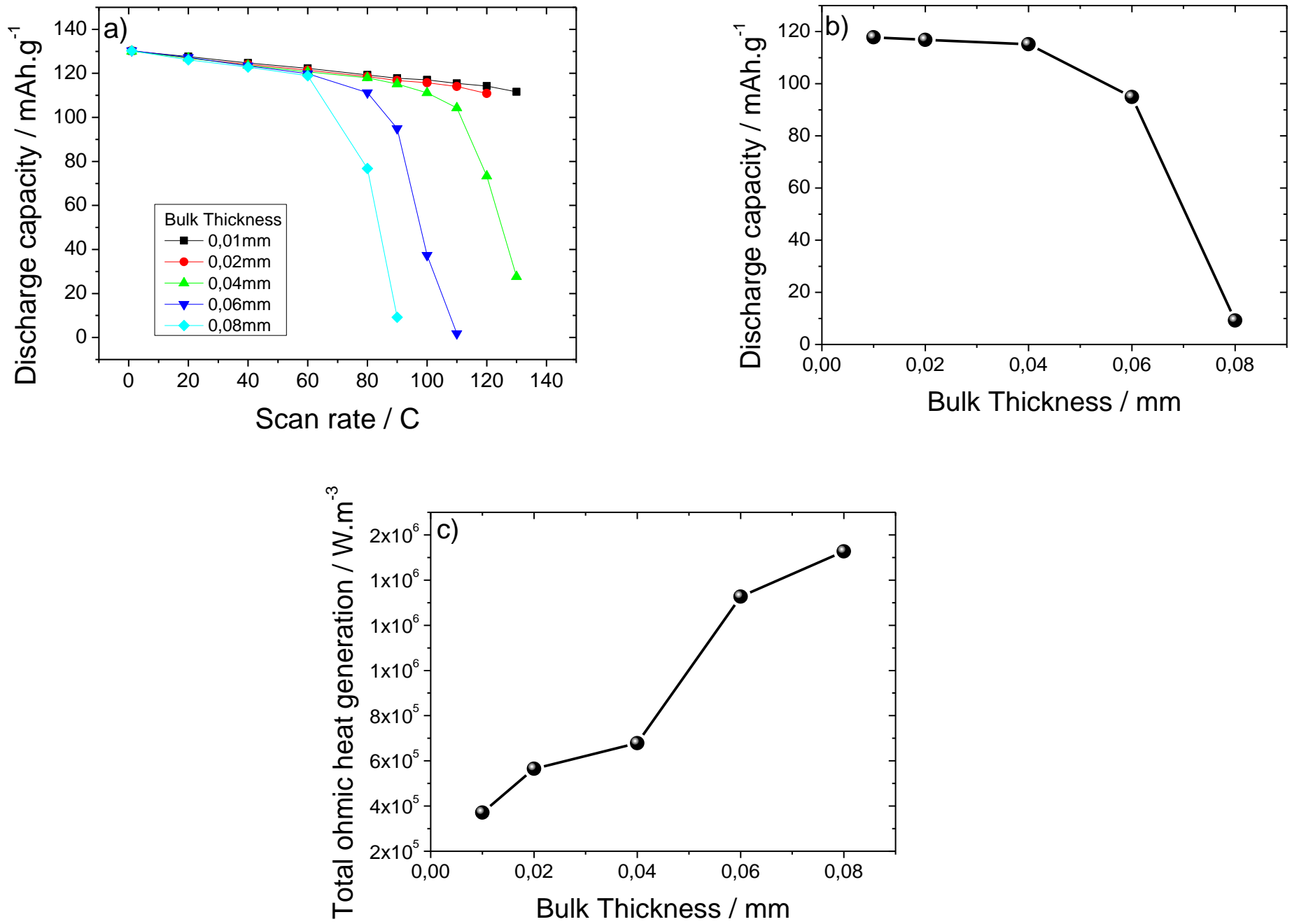
Figure 9 - a) Discharge capacity values as a function of C-rate and b) as a function of bulk thickness variation at 90C-rate for the different geometries. c) Total ohmic heat generation as a function of bulk thickness variation at 90C-rate.

It is observed that the value of the discharge capacity decreases with decreasing separator thickness due to the different pillar heights and spacing between them in order to keep constant the volume of solid material in the separator. As the bulk thickness increases, there is also a decrease in the height of the column that will contribute to a decrease in the capacity of the battery. In addition, it is determined that this parameter has a high impact on battery performance due to increased ions density and corresponding effect in the intercalation process. As consequence of this effect, Figure 9c) shows the total ohmic heat generated as a function of bulk thickness, demonstrating that as the bulk thickness of the separator increases there is an increase in the total heat dissipated, due to the increased distance the ions have to travel within the separator for intercalation. This increase in distance leads to a higher electrical resistance and, consequently, to an increase of the dissipated heat.

Thus, from an experimental and theoretical approach, the impact of geometric parameters (pillar diameter and height and bulk thickness) on the pillar separator microstructure was demonstrated, allowing to improve cycling behavior of lithium-ion batteries based on 3D porous separators. However, the bulk thickness the parameter that affects at most the capacity and performance of the battery. An increase in the bulk thickness of the separator leads to a decrease in the value of the capacity and battery performance at high discharge rates. This phenomenon is due to the increase in the distance that the ions must travel through the bulk thickness of the separator until reaching the pillars in the discharge process. Thus, it is concluded that pattern separator membranes based on surface pillars allow to improve battery performance. 


\section{Conclusions}

Taking into account that the battery separator has a high impact on battery performance, this work demonstrates the effect of separator microstructuring with pillars with varying geometrical characteristics, such as diameter, height and bulk thickness. The different pillar microstructures were manufactured by template patterning and theoretical computer simulations were carried out to quantify the effect of these parameters on the value of the discharge capacity. It was experimentally demonstrated that the different pillar microstructured separator membranes lead to different uptake value (150-325\%), ionic conductivity value $\left(0.8-1.6 \mathrm{mS} \cdot \mathrm{cm}^{-1}\right)$ and cycling battery performances in half-cells and that the discharge capacitive value increases when compared to separators without pillars. It was found that all geometrical parameters affect battery performance, the parameter with the largest impact being the bulk thickness of the separator due to the influence on the distance that ions have to travel during the lithium ion intercalation process. The discharge capacity losses associated with the increase in resistance to ion mobility caused by the increase in the bulk thickness of the separator are more significant compared to variations in pillar diameter and height.

Thus, it is concluded that the pillar microstructure leads to improved battery performance, allowing to suitably tune battery discharge capacity by tailoring geometrical parameters of the separator pillar microstructure. It is then concluded that patterning of separators with pillar microstructures represent a suitable approach for next generation of highperformance lithium-ion batteries.

\section{Acknowledgments}

The authors thank the FCT (Fundação para a Ciência e Tecnologia) for financial support under the framework of Strategic Funding grants UID/FIS/04650/2020, UID/EEA/04436/2020 and UID/QUI/0686/2020 and under projects POCI-01-0145FEDER-028157, PTDC/FIS-MAC/28157/2017 funded by national funds through FCT and by the ERDF through the COMPETE2020 - Programa Operacional Competitividade e Internacionalização (POCI). The authors also thank the FCT for financial support under grants SFRH/BPD/112547/2015 (C.M.C.) and SFRH/BD/141136/2018 (TMA), and FCT investigator contracts CEECIND/00833/ 2017 (RG). Financial support from the Basque Government Industry and Education Departments under the ELKARTEK, HAZITEK and PIBA (PIBA-2018-06) programs, respectively, are acknowledged. D. Miranda was also 
supported by Portuguese national funds (PIDDAC), through the FCT - Fundação para a Ciência e Tecnologia and FCT/MCTES under the scope of the project UIDB/05549/2020.

\section{Annex I: Nomenclature}

\begin{tabular}{|c|c|}
\hline \multicolumn{2}{|c|}{ List of symbols } \\
\hline $\mathrm{a}$ & specific interfacial area, $\mathrm{m}^{2} \cdot \mathrm{m}^{-3}$ \\
\hline A & cross-sectional area of the battery, $\mathrm{m}^{2}$ \\
\hline $\mathrm{C}_{\mathrm{L}}$ & concentration of $\mathrm{Li}$ ions in the electrolyte, $\mathrm{mol} \cdot \mathrm{m}^{-3}$ \\
\hline $\mathrm{C}_{\mathrm{E}}$ & concentration of $\mathrm{Li}$ ions in the electrode, $\mathrm{mol} \cdot \mathrm{m}^{-3}$ \\
\hline $\mathrm{D}$ & diffusion coefficient of the salt in the electrolyte, $\mathrm{m}^{2} \cdot \mathrm{s}^{-1}$ \\
\hline $\mathrm{D}_{\mathrm{LI}}$ & diffusion coefficient of $\mathrm{Li}$ ions in the electrode $\mathrm{m}^{2} \cdot \mathrm{s}^{-1}$ \\
\hline $\mathrm{F}$ & Faraday’s constant, $96487 \mathrm{C} \cdot \mathrm{mol}^{-1}$ \\
\hline$f_{ \pm}$ & activity of the salt in the electrolyte, $\mathrm{mol} \cdot \mathrm{m}^{-3}$ \\
\hline$H p$ & pillar height, $\mathrm{m}$ \\
\hline $\mathbf{i}_{\mathrm{E}}$ & current density in the electrode, $\mathrm{A} \cdot \mathrm{m}^{-2}$ \\
\hline $\mathbf{i}_{\mathrm{L}}$ & current density in the electrolyte phase, $\mathrm{A} \cdot \mathrm{m}^{-2}$ \\
\hline $\mathrm{I}_{\text {TOTAL }}$ & total current density, $\mathrm{A} \cdot \mathrm{m}^{-2}$ \\
\hline $\mathrm{j}_{\mathrm{Li}}^{+}$ & pore wall flux of $\mathrm{Li}$ ions, $\mathrm{mol} \cdot \mathrm{cm}^{-2} \cdot \mathrm{s}^{-1}$ \\
\hline $\mathrm{L}$ & width, m \\
\hline$d_{b a t t}$ & cross-section diameter of the battery, $\mathrm{m}$ \\
\hline$D p$ & pillar diameter, $\mathrm{m}$ \\
\hline M & mass transport flux, $\mathrm{mol} \cdot \mathrm{m}^{-2}$ \\
\hline r_col & radius of each column, m \\
\hline $\mathrm{R}$ & reaction term of the mass balance equation, $\mathrm{mol} \cdot \mathrm{m}^{-3} \cdot \mathrm{s}^{-1}$ \\
\hline $\mathrm{R}$ & gas constant, $8,314 \mathrm{~J} \cdot \mathrm{mol}^{-1} \cdot \mathrm{K}^{-1}$ \\
\hline $\mathrm{R}_{\mathrm{f}}$ & film resistance, $\Omega \mathrm{m}^{2}$ \\
\hline $\mathrm{R}_{\mathrm{i}}$ & radius of the electrode spherical particles, $\mathrm{m}$ \\
\hline $\mathrm{T}$ & temperature, $\mathrm{K}$ \\
\hline $\mathrm{t}$ & time, s \\
\hline$T b$ & separator base thickness, $\mathrm{m}$ \\
\hline$t_{+}^{0}$ & transport number of the positive ions \\
\hline$u^{0}$ & open circuit voltage, $\mathrm{V}$ \\
\hline
\end{tabular}




\begin{tabular}{|c|c|}
\hline \multirow{2}{*}{$\begin{array}{l}\text { p } \\
\text { brugg }\end{array}$} & Porosity of the separator \\
\hline & Brugg parameter in the electrodes \\
\hline$E_{a d, i}$ & activation energy for diffusion of electrodes $i(i=\mathrm{a}, \mathrm{c}), \mathrm{J} \cdot \mathrm{mol}^{-1}$ \\
\hline$E_{a k, i}$ & activation energy for reation of electrodes $i(i=\mathrm{a}, \mathrm{c}), \mathrm{J} \cdot \mathrm{mol}^{-1}$ \\
\hline \multicolumn{2}{|r|}{ Greek symbols } \\
\hline$\varepsilon_{\mathrm{i}}$ & porosity of region $i(i=\mathrm{a}, \mathrm{s}, \mathrm{c})$ \\
\hline$\varepsilon_{\mathrm{f}, \mathrm{i}}$ & volume fraction of the fillers in the electrode $i(i=\mathrm{a}, \mathrm{s}, \mathrm{c})$ \\
\hline$\tau$ & tortuosity of the separator \\
\hline$\eta$ & over-potential, V \\
\hline$\varphi_{\mathrm{E}}$ & potential of the electrodes, $\mathrm{V}$ \\
\hline$\varphi_{\mathrm{L}}$ & potential of the electrolyte, $\mathrm{V}$ \\
\hline$\kappa_{1}$ & ionic conductivity of the electrolyte, $\mathrm{S} \cdot \mathrm{m}^{-1}$ \\
\hline$\kappa_{\mathrm{ef}, \mathrm{i}}$ & effective ionic conductivity of the electrolyte $i(i=\mathrm{a}, \mathrm{c}), \mathrm{S} \cdot \mathrm{m}^{-1}$ \\
\hline$\kappa_{\mathrm{f}}$ & effective ionic conductivity of the separator polymer film, $\mathrm{S} \cdot \mathrm{m}^{-1}$ \\
\hline$\sigma$ & electronic conductivity of the solid phase of the electrode $i(i=\mathrm{a}, \mathrm{s}, \mathrm{c}), \mathrm{S} \cdot \mathrm{m}^{-1}$ \\
\hline$\sigma_{\mathrm{ef}, \mathrm{i}}$ & $\begin{array}{l}\text { effective electronic conductivity of the solid phase of the electrode } i(i=\mathrm{a}, \mathrm{s}, \mathrm{c}) \text {, } \\
\mathrm{S} \cdot \mathrm{m}^{-1}\end{array}$ \\
\hline$\rho_{\mathrm{i}}$ & density of battery components $i(i=\mathrm{a}, \mathrm{s}, \mathrm{c}), \mathrm{kg} \cdot \mathrm{m}^{-3}$ \\
\hline \multicolumn{2}{|r|}{ Subscripts referring specific components of the battery and initial condition } \\
\hline $\mathrm{a}$ & anode \\
\hline $\mathrm{c}$ & cathode \\
\hline s & separator \\
\hline 0 & initial condition \\
\hline
\end{tabular}




\section{References}

[1] I.A. Choudhury, S. Hashmi, Encyclopedia of Renewable and Sustainable Materials, Elsevier Science2020.

[2] A.M. Omer, Energy use and environmental impacts: A general review, Journal of Renewable and Sustainable Energy 1(5) (2009) 053101.

[3] F. Perera, Pollution from Fossil-Fuel Combustion is the Leading Environmental Threat to Global Pediatric Health and Equity: Solutions Exist, International Journal of Environmental Research and Public Health 15(1) (2018) 16.

[4] D. Gielen, F. Boshell, D. Saygin, M.D. Bazilian, N. Wagner, R. Gorini, The role of renewable energy in the global energy transformation, Energy Strategy Reviews 24 (2019) 38-50.

[5] T.M. Gür, Review of electrical energy storage technologies, materials and systems: challenges and prospects for large-scale grid storage, Energy \& Environmental Science 11(10) (2018) 2696-2767.

[6] B. Diouf, R. Pode, Potential of lithium-ion batteries in renewable energy, Renewable Energy 76 (2015) 375-380.

[7] Y. Liang, C.-Z. Zhao, H. Yuan, Y. Chen, W. Zhang, J.-Q. Huang, D. Yu, Y. Liu, M.-M. Titirici, Y.-L. Chueh, H. Yu, Q. Zhang, A review of rechargeable batteries for portable electronic devices, InfoMat 1(1) (2019) 6-32.

[8] X. Han, L. Lu, Y. Zheng, X. Feng, Z. Li, J. Li, M. Ouyang, A review on the key issues of the lithium ion battery degradation among the whole life cycle, eTransportation 1 (2019) 100005.

[9] A. Gören, C.M. Costa, M.M. Silva, S. Lanceros-Méndez, State of the art and open questions on cathode preparation based on carbon coated lithium iron phosphate, Composites Part B: Engineering 83 (2015) 333-345.

[10] C.M. Costa, Y.-H. Lee, J.-H. Kim, S.-Y. Lee, S. Lanceros-Méndez, Recent advances on separator membranes for lithium-ion battery applications: From porous membranes to solid electrolytes, Energy Storage Materials 22 (2019) 346-375. [11] C.M. Costa, E. Lizundia, S. Lanceros-Méndez, Polymers for advanced lithium-ion batteries: State of the art and future needs on polymers for the different battery components, Progress in Energy and Combustion Science 79 (2020) 100846. 
[12] D. Miranda, C.M. Costa, A.M. Almeida, S. Lanceros-Méndez, Modeling separator membranes physical characteristics for optimized lithium ion battery performance, Solid State Ionics 278 (2015) 78-84.

[13] A. Jana, D.R. Ely, R.E. García, Dendrite-separator interactions in lithium-based batteries, Journal of Power Sources 275 (2015) 912-921.

[14] M.F. Lagadec, R. Zahn, S. Müller, V. Wood, Topological and network analysis of lithium ion battery components: the importance of pore space connectivity for cell operation, Energy \& Environmental Science 11(11) (2018) 3194-3200.

[15] J. Ni, A. Dai, Y. Yuan, L. Li, J. Lu, Three-Dimensional Microbatteries beyond Lithium Ion, Matter 2(6) (2020) 1366-1376.

[16] M.S. Saleh, J. Li, J. Park, R. Panat, 3D printed hierarchically-porous microlattice electrode materials for exceptionally high specific capacity and areal capacity lithium ion batteries, Additive Manufacturing 23 (2018) 70-78.

[17] Z. Wang, J. Ni, L. Li, J. Lu, Theoretical Simulation and Modeling of ThreeDimensional Batteries, Cell Reports Physical Science (2020) 100078.

[18] V. Zadin, H. Kasemägi, A. Aabloo, D. Brandell, Modelling electrode material utilization in the trench model 3D-microbattery by finite element analysis, Journal of Power Sources 195(18) (2010) 6218-6224.

[19] P. Priimägi, D. Brandell, S. Srivastav, A. Aabloo, H. Kasemägi, V. Zadin, Optimizing the design of 3D-pillar microbatteries using finite element modelling, Electrochimica Acta 209 (2016) 138-148.

[20] K. McKelvey, A.A. Talin, B. Dunn, H.S. White, Microscale 2.5D Batteries, Journal of The Electrochemical Society 164(12) (2017) A2500-A2503.

[21] P. Priimägi, H. Kasemägi, A. Aabloo, D. Brandell, V. Zadin, Thermal Simulations of Polymer Electrolyte 3D Li-Microbatteries, Electrochimica Acta 244 (2017) 129-138. [22] R. Gonçalves, T. Marques-Almeida, D. Miranda, M.M. Silva, V.F. Cardoso, C.M. Costa, S. Lanceros-Méndez, Enhanced performance of fluorinated separator membranes for lithium ion batteries through surface micropatterning, Energy Storage Materials 21 (2019) 124-135.

[23] V.C. Pinto, P.J. Sousa, V.F. Cardoso, G. Minas, Optimized SU-8 processing for low-cost microstructures fabrication without cleanroom facilities, Micromachines 5(3) (2014) 738-755. 
[24] C. Ribeiro, C.M. Costa, D.M. Correia, J. Nunes-Pereira, J. Oliveira, P. Martins, R. Gonçalves, V.F. Cardoso, S. Lanceros-Méndez, Electroactive poly(vinylidene fluoride)based structures for advanced applications, Nature Protocols 13(4) (2018) 681-704. [25] C.M. Costa, L.C. Rodrigues, V. Sencadas, M.M. Silva, J.G. Rocha, S. LancerosMéndez, Effect of degree of porosity on the properties of poly(vinylidene fluoridetrifluorethylene) for Li-ion battery separators, Journal of Membrane Science 407-408 (2012) 193-201.

[26] X. Zhang, P.N. Ross, R. Kostecki, F. Kong, S. Sloop, J.B. Kerr, K. Striebel, E.J. Cairns, F. McLarnon, Diagnostic Characterization of High Power Lithium-Ion Batteries for Use in Hybrid Electric Vehicles, Journal of The Electrochemical Society 148(5) (2001) A463.

[27] M. Doyle, Modeling of Galvanostatic Charge and Discharge of the Lithium/Polymer/Insertion Cell, Journal of The Electrochemical Society 140(6) (1993) 1526.

[28] T.F. Fuller, Simulation and Optimization of the Dual Lithium Ion Insertion Cell, Journal of The Electrochemical Society 141(1) (1994) 1.

[29] D. Miranda, C.M. Costa, S. Lanceros-Mendez, Lithium ion rechargeable batteries: State of the art and future needs of microscopic theoretical models and simulations, Journal of Electroanalytical Chemistry 739 (2015) 97-110.

[30] R.E. Gerver, J.P. Meyers, Three-Dimensional Modeling of Electrochemical Performance and Heat Generation of Lithium-Ion Batteries in Tabbed Planar Configurations, Journal of The Electrochemical Society 158(7) (2011) A835. [31] S. Bae, H.D. Song, I. Nam, G.-P. Kim, J.M. Lee, J. Yi, Quantitative performance analysis of graphite-LiFePO4 battery working at low temperature, Chemical Engineering Science 118 (2014) 74-82.

[32] M. Kundu, C.M. Costa, J. Dias, A. Maceiras, J.L. Vilas, S. Lanceros-Méndez, On the Relevance of the Polar $\beta$-Phase of Poly(vinylidene fluoride) for High Performance Lithium-Ion Battery Separators, The Journal of Physical Chemistry C 121(47) (2017) 26216-26225.

[33] S.W. Choi, J.R. Kim, Y.R. Ahn, S.M. Jo, E.J. Cairns, Characterization of Electrospun PVdF Fiber-Based Polymer Electrolytes, Chemistry of Materials 19(1) (2007) 104-115.

[34] B.-Y. Chang, S.-M. Park, Electrochemical Impedance Spectroscopy, Annual Review of Analytical Chemistry 3(1) (2010) 207-229. 
[35] C. Fongy, A.C. Gaillot, S. Jouanneau, D. Guyomard, B. Lestriez, Ionic vs Electronic Power Limitations and Analysis of the Fraction of Wired Grains in $\mathrm{LiFePO}[\mathrm{sub} 4]$ Composite Electrodes, Journal of The Electrochemical Society 157(7) (2010) A885.

[36] A. Gören, J. Mendes, H.M. Rodrigues, R.E. Sousa, J. Oliveira, L. Hilliou, C.M. Costa, M.M. Silva, S. Lanceros-Méndez, High performance screen-printed electrodes prepared by a green solvent approach for lithium-ion batteries, Journal of Power Sources 334 (2016) 65-77.

[37] R.E. Sousa, J. Oliveira, A. Gören, D. Miranda, M.M. Silva, L. Hilliou, C.M. Costa, S. Lanceros-Mendez, High performance screen printable lithium-ion battery cathode ink based on C-LiFePO4, Electrochimica Acta 196 (2016) 92-100. 